\title{
Formation and growth of nucleated particles into cloud condensation nuclei: model-measurement comparison
}

\author{
D. M. Westervelt ${ }^{1}$, J. R. Pierce ${ }^{2}$, I. Riipinen ${ }^{1,3}$, W. Trivitayanurak ${ }^{4}$, A. Hamed ${ }^{5,6}$, M. Kulmala ${ }^{7}$, A. Laaksonen ${ }^{7,8}$, \\ S. Decesari ${ }^{9}$, and P. J. Adams ${ }^{1}$ \\ ${ }^{1}$ Center for Atmospheric Particle Studies (CAPS), Carnegie Mellon University, Pittsburgh, PA, USA \\ ${ }^{2}$ Department Atmospheric Science, Colorado State University, Fort Collins, CO, USA \\ ${ }^{3}$ Department of Applied Environmental Science, University of Stockholm, Stockholm, Sweden \\ ${ }^{4}$ Department of Highways, Bangkok, Thailand \\ ${ }^{5}$ Department of Applied Physics, University of Eastern Finland, Kuopio, Finland \\ ${ }^{6}$ Leibniz Institute for Tropospheric Research, Department of Physics, Leipzig, Germany \\ ${ }^{7}$ Department of Physics, University of Helsinki, Helsinki, Finland \\ ${ }^{8}$ Finnish Meteorological Institute, Helsinki, Finland \\ ${ }^{9}$ Institute of Atmospheric Sciences and Climate, Italian National Research Council (ISAC-CNR), Bologna, Italy
}

Correspondence to: P. J. Adams (petera@andrew.cmu.edu)

Received: 4 March 2013 - Published in Atmos. Chem. Phys. Discuss.: 27 March 2013

Revised: 2 July 2013 - Accepted: 5 July 2013 - Published: 8 August 2013

\begin{abstract}
Aerosol nucleation occurs frequently in the atmosphere and is an important source of particle number. Observations suggest that nucleated particles are capable of growing to sufficiently large sizes that they act as cloud condensation nuclei $(\mathrm{CCN})$, but some global models have reported that $\mathrm{CCN}$ concentrations are only modestly sensitive to large changes in nucleation rates. Here we present a novel approach for using long-term size distribution observations to evaluate a global aerosol model's ability to predict formation rates of $\mathrm{CCN}$ from nucleation and growth events. We derive from observations at five locations nucleation-relevant metrics such as nucleation rate of particles at diameter of $3 \mathrm{~nm}\left(J_{3}\right)$, diameter growth rate (GR), particle survival probability (SP), condensation and coagulation sinks, and $\mathrm{CCN}$ formation rate $\left(\mathrm{J}_{100}\right)$. These quantities are also derived for a global microphysical model, GEOS-Chem-TOMAS, and compared to the observations on a daily basis. Using GEOSChem-TOMAS, we simulate nucleation events predicted by ternary (with a $10^{-5}$ tuning factor) or activation nucleation over one year and find that the model slightly understates the observed annual-average $\mathrm{CCN}$ formation mostly due to bias in the nucleation rate predictions, but by no more than $50 \%$ in the ternary simulations. At the two locations expected to be most impacted by large-scale regional nucleation, Hyytiälä
\end{abstract}

and San Pietro Capofiume, predicted annual-average CCN formation rates are within 34 and $2 \%$ of the observations, respectively. Model-predicted annual-average growth rates are within $25 \%$ across all sites but also show a slight tendency to underestimate the observations, at least in the ternary nucleation simulations. On days that the growing nucleation mode reaches $100 \mathrm{~nm}$, median single-day survival probabilities to $100 \mathrm{~nm}$ for the model and measurements range from less than 1-6\% across the five locations we considered; however, this does not include particles that may eventually grow to $100 \mathrm{~nm}$ after the first day. This detailed exploration of new particle formation and growth dynamics adds support to the use of global models as tools for assessing the contribution of microphysical processes such as nucleation to the total number and $\mathrm{CCN}$ budget.

\section{Introduction}

Atmospheric aerosols are known to perturb climate in several ways. The largest current uncertainty in climate forcing is the aerosol indirect effect (AIE), which is broken down into the cloud albedo effect and the lifetime effect (Twomey, 1977; Albrecht, 1989). With increasing aerosol 


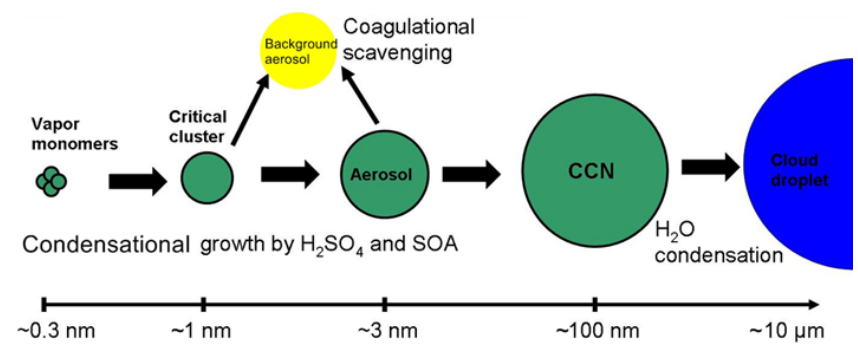

Fig. 1. Dynamics of new particle formation from vapor to cloud droplet. Two competing processes determining the fate of freshly formed atmospheric nuclei are condensational growth (eventually forming $\mathrm{CCN}$ ) or coagulational scavenging, which results in the loss of the nuclei.

number concentrations, a subset of which act as cloud condensation nuclei (CCN), brighter and potentially longer-lived clouds are formed. In order for aerosols to exert these influences on clouds, they are either introduced into the atmosphere by direct emission or gas-to-particle conversion (nucleation) where they may grow to sufficiently large sizes to act as CCN (Kerminen et al., 2005; Pierce and Adams, 2007; Kuang et al., 2009). A competition between condensational growth and coagulational loss determines a particle's survival probability during growth through a certain size range (Fig. 1). Although subject to the same dynamic processes, the fates of particles formed via primary emission and nucleation can be quite different. Nucleated particles have initial sizes on the order of a few nanometers or less, which is much smaller than typical primary emission size ranges (Kulmala et al., 2000, 2004a, 2013; Mäkelä et al.,1997.; Vehkamaki et al., 2004). As a result, in order for particles formed via nucleation to act as $\mathrm{CCN}$, they must grow by condensation while avoiding loss by coagulation for a longer amount of time and through a larger range of sizes than primary emissions. Since freshly nucleated particles are small, they are highly diffusive and prone to collide with pre-existing particles. Therefore, coagulation is very efficient between fresh nuclei and larger particles, compounding the increased time that nucleated particles require to grow to $\mathrm{CCN}$ sizes. Ambient measurements presented in Kuang et al. (2009) highlight the importance of coagulation as at least $80 \%$ of the nucleated particles on average are lost by coagulation before the nucleation mode reached $\mathrm{CCN}$ sizes in the cases that they studied, even during days with high growth rates.

Recent work has suggested there is a potential discrepancy between aerosol models and observations, and between multiple aerosol models themselves, regarding the number of CCN formed from nucleated particles. For example, the aforementioned Kuang et al. (2009) study reported survival probabilities up to $20 \%$ for measured nucleation events in Atlanta, GA, and suggested inaccuracies in model-predicted organic condensation growth rates as a possible explanation for the difference with the model results of Pierce and
Adams (2009b). Pierce and Adams (2009b) showed low probabilities ( $10 \%$ or less) of particles growing to CCN sizes when nucleation parameterizations were active in the simulations. Using a global aerosol model, they also found that global CCN concentrations are more responsive to uncertainties in primary emissions than uncertainties in nucleation, reporting a $12 \%$ global average $\mathrm{CCN}$ sensitivity when varying the nucleation rate by six orders of magnitude. Moreover, the low sensitivity was attributed to decreasing survival probabilities with increasing nucleation rates due to increased coagulation and decreased growth rates at faster nucleation rates. In the extreme case of fast ternary nucleation rates of Napari et al. (2002), particle survival probabilities were on the order of $10^{-8}$. The reason for these low survival probabilities is a nucleation-CCN feedback mechanism in which higher nucleation rates lead to faster coagulation removal rates and a higher condensation sink, which in turn lowers survival probability and dampens CCN formation.

The differing outcomes between models and measurements as well as between different models are likely caused by several factors. First, models including the one employed in Pierce and Adams (2009b) may suffer from the lack of a robust nucleation theory. As will be explained, observed nucleation events cannot fully be explained by theory. Secondly, observational studies are often limited to a single location and a short length of time, and may focus on dramatic growth events that are not necessarily representative of the longer climatology. Global models, on the other hand, typically report averages over the entire troposphere including the free troposphere. Third, models may also be inaccurate in secondary organic aerosol (SOA) formation, which is essential for the growth of nucleated particles to $\mathrm{CCN}$ sizes (Kulmala et al., 2004b; Kuang et al., 2009; Riipinen et al., 2011). The most recent estimates of the SOA budget have constrained it to fall within 50-230 $\mathrm{Tg} \mathrm{SOA} \mathrm{yr}^{-1}$ (Spracklen et al., 2011), although other studies have reported ranges as low as $12-70 \mathrm{Tg} \mathrm{SOA} \mathrm{yr}^{-1}$ (Kanakidou et al., 2005). Fourth, the metrics of comparison between measurements and models are often not the same, making a side-by-side comparison erroneous or difficult. This is especially true in model-model comparisons of the contribution of nucleation to $\mathrm{CCN}$, in which the problem is rooted in the difference between the fractional contribution of nucleation to $\mathrm{CCN}$ (e.g., Merikanto et al., 2009) and the sensitivity of CCN to changes in nucleation (e.g., Pierce et al., 2009b).

The science behind nucleation theory is not well understood and many plausible yet not fully robust formulations have been proposed. The importance of sulfuric acid as a primary nucleating species has been confirmed (Berndt et al., 2005; Kuang et al., 2008; Sipilä et al., 2010; Vuollekoski et al., 2010; Weber et al., 1996). Additional evidence has shown that low volatility organic vapors (Paasonen et al., 2010; Zhang et al., 2004), amines (Bzdek et al., 2010; Kurtén et al., 2008, Kirkby et al., 2011), and ammonia (Ball et al., 1999.; Erupe et al., 2010, Kirkby et al., 2011) may also play 
significant roles in the initial steps of atmospheric nucleation. Recently, Zhao et al. (2011) observed neutral clusters of sulfuric acid and amines plus ammonia in atmospheric measurements for the first time, and Chen et al. (2012) proposed an acid-base nucleation mechanism involving these two chemical species which achieved nucleation rate closure to within a factor of 10. Additionally, Kulmala et al. (2013) have observed atmospheric nanoparticles and clusters as small as $1 \mathrm{~nm}$ in diameter and concluded that these particles are most likely comprised of sulfuric acid, strong bases, and organic vapors.

Binary and ternary homogenous nucleation theories have been proposed to explain nucleation rates on a global scale in the atmosphere. Binary homogenous nucleation involves the supersaturation of solutions of sulfuric acid and water in a binary system (Vehkamaki et al., 2004). Ternary homogenous nucleation, such as the parameterization proposed by Napari et al. (2002), adds a third nucleating species, typically ammonia $\left(\mathrm{NH}_{3}\right)$. The original ternary formulation of Napari et al. (2002) showed high biases in predictions of nucleation rates and aerosol number concentrations (Merikanto et al., 2007; Jung et al., 2008). A modified version with a globally constant nucleation rate tuning factor of $10^{-5}$ has been incorporated into a regional aerosol model and shows reasonable agreement (Jung et al., 2010) with observations. The following results for ternary nucleation presented in this work include the $10^{-5}$ tuning factor, which was chosen on the basis of improvement of nucleation rate and aerosol number concentration predictions. Other possible nucleation parameterizations include empirical methods such as activation nucleation (Kulmala et al., 2000), which is often applied in the planetary boundary layer (PBL) in conjunction with the binary scheme of Vehkamaki et al. (2004) in the free troposphere.

Adding to the poor understanding of atmospheric nucleation is the role of charged particles. Recently, Yu and Turco (2011) reviewed previous findings and suggested a $100 \%$ contribution of ions to new particle formation at Hyytiälä. However, other studies have found no greater than a $10 \%$ contribution of ion nucleation to aerosol formation rates in similar continental boundary layer environments (Gagné et al., 2008, 2010; Laakso et al., 2007; Manninen et al., 2009). Kirkby et al. (2011) showed that ion-induced binary nucleation is not likely to play a role in boundary layer nucleation but may be important for the free troposphere at temperatures around $250 \mathrm{~K}$. Kazil et al. (2010) suggested that ions may play an important role in nucleation in the marine boundary layer; however, to our knowledge this has not been explored yet by observations.

Freshly formed nuclei have very short lifetimes in the atmosphere (less than a few hours for 1-5 nm particles in the boundary layer) due to loss by coagulation with larger particles. Thus, they must grow quickly to larger sizes if they are to influence CCN concentrations. Once nuclei are formed, growth is typically dominated by condensation of sulfuric acid vapor and low volatility organic vapors. At some locations, organic condensation accounts for nearly the entire aerosol growth rate (Kuang et al., 2009; Riipinen et al., 2011). Diameter growth rates from 3 to $25 \mathrm{~nm}$ during nucleation events in 2007 at Hyytiälä, Finland, have a median value around $2-3 \mathrm{~nm} \mathrm{~h}^{-1}$, although median rates much faster and slower have been reported elsewhere. For example, growth rates up to $9 \mathrm{~nm} \mathrm{~h}^{-1}$ have been reported for a continental location in South Africa (Vakkari et al., 2011). Coagulational growth of nucleated particles can also occur when similar-sized small nuclei interact with each other, although this rate of coagulation growth is much slower than condensation growth and can generally be ignored (Dal Maso et al., 2002; Kerminen and Kulmala, 2002; Stolzenburg et al., 2005). More commonly, coagulation scavenging occurs, which is the dominant sink of freshly formed nuclei compared to deposition, but is highly dependent on atmospheric conditions (Pierce and Adams, 2007). Understanding the growth and loss processes, which make up a particle's survival probability, is the most important step in understanding the contribution of nucleation events to aerosol number and $\mathrm{CCN}$ concentrations.

To date, modeling studies aiming to quantify $\mathrm{CCN}$ formation from nucleation have been limited by a lack of detailed evaluation of modeling output against ambient observations and have suffered from the nonlinear nature of aerosol microphysics when making sensitivity calculations. Because of feedbacks on condensation and coagulation, the common methodology of "turning off" nucleation as a control experiment against a nucleation-active simulation is useful for sensitivity calculations (percent changes in $\mathrm{CCN}$ concentrations due to changes in the nucleation rate) but is not equal to a fractional contribution of nucleation to CCN. Recently, Lee et al. (2013) compiled 28 model parameters covering all important aerosol processes and ran Monte Carlo simulations to determine the uncertainty in $\mathrm{CCN}$ concentrations due to each parameter. They found that although roughly $40 \%$ of $\mathrm{CCN}$ are attributed to nucleation, $\mathrm{CCN}$ are generally insensitive to the nucleation rates across a wide range of boundary layer and free tropospheric nucleation assumptions. Other studies have reported similar CCN sensitivities to nucleation ranging from 3 to $60 \%$ (Yu and Luo, 2009; Makkonen et al., 2009; Merikanto et al., 2009; Spracklen et al., 2010; Wang and Penner, 2009). Each of these studies used different models and often significantly different inputs, assumptions, and metrics for assessing CCN sensitivity, making model intercomparison difficult. In particular, the domain over which nucleation is changed (boundary layer or free troposphere), $\mathrm{CCN}$ activation scheme, and the definition of what counts as a "nucleated" particle can influence results significantly. For example, Pierce and Adams (2009b) chose binary and ternary nucleation as the two endpoints for a sensitivity study, whereas others such as Spracklen et al. (2008) turn nucleation off entirely in a global model as a control against simulations with any particular active nu- 
Table 1. Locations for model comparison.

\begin{tabular}{llll}
\hline & Simulated year & Meteorological fields & Data reference \\
\hline Pittsburgh, USA (PGH) & Jul 2001-Jun 2002 & GEOS3 & Stanier et al. (2004) \\
Hyytiälä, Finland (HYY) & Jan 2007-Jan 2008 & GEOS5 & Dal Maso et al. (2005) \\
Atlanta, USA (ATL) & Jan 1999-Jan 2000 & GEOS3 & Woo et al. (2001) \\
St. Louis, USA (STL) & Jan 2002-Jan 2003 & GEOS3 & Qian et al. (2007) \\
San Pietro Capofiume, Italy (SPC) & Apr 2002-Mar 2003 & GEOS3 & Laaksonen et al. (2005) \\
\hline
\end{tabular}

cleation theory. Spracklen et al. (2008) found the influence of nucleation on $\mathrm{CCN}(0.2 \%)$ to be as low as $3 \%$ and as large as $20 \%$. However, these values refer only to the sensitivity of $\mathrm{CCN}$ to activation nucleation in the boundary layer. Merikanto et al. (2009) found that $45 \%$ of CCN $(0.2 \%)$ originate from nucleation, although they note that most of that $(35 \%$ of $\mathrm{CCN})$ comes from the free and upper troposphere and not the boundary layer. Yu and Luo (2009), who found the highest contribution to $\mathrm{CCN}$ of all of the studies, assumed that $5 \%$ of the sulfate formed in plumes on sub-grid spatial scales (e.g., Stevens et al., 2012) exists in the nucleation mode and counts towards the nucleation contribution to $\mathrm{CCN}$. Other cited studies include only regional-scale (i.e., grid-scale resolved) nucleation events in the nucleation contribution. Additionally, the aerosol microphysics model employed in Yu and Luo (2009) used a fixed log-normal mode to prescribe primary organic aerosol size, resulting in a simplified treatment of the coagulation of nucleation particles with larger, primary particles. Varying treatments of particle activation into CCN may also play a role. For example, Makkonen et al. (2009) use the ECHAM5-HAM cloud droplet activation scheme and report $\mathrm{CCN}$ enhancements of up to $50 \%$ in the boundary layer between activation and binary nucleation. That version of ECHAM5-HAM used a cloud droplet activation scheme that allows nucleated particles to become $\mathrm{CCN}$ active as soon as they grow to a wet radius of $35 \mathrm{~nm}$ and treats all particles with a wet radius larger than $35 \mathrm{~nm}$ as equal for purposes of activation. This translates to roughly a $50 \mathrm{~nm}$ dry activation diameter, a value that may tend to overstate the impact of nucleation on CCN formation. Finally, Wang and Penner (2009) use the IMPACT aerosol model incorporated into the NCAR CCSM3 to determine a $5.3 \%$ enhancement in $\mathrm{CCN}$ due to nucleation.

The Makkonen et al. (2009) study and the Yu and Luo (2009) study show the highest CCN sensitivity to nucleation but also use very different assumptions in terms of activation scheme and what counts as nucleation. The works of Spracklen et al. (2010), Spracklen et al. (2008), and Merikanto et al. (2009) find free troposphere nucleation to be a major source of their nucleated particles growing to $\mathrm{CCN}$, something that the Pierce and Adams (2009) study does not explicitly test. Bearing in mind the differences in the reported calculations, the 3-60\% range in CCN sensitivity to nucleation may be more apparent than real. Although the diver- sity of simulations is useful, we suspect that models would agree more closely with each other when using a consistent basis of comparison. In particular, omitting the Makkonen et al. (2009) and Yu and Luo (2009) studies, the range of influence of boundary layer nucleation on $\mathrm{CCN}$ is much narrower.

Therefore, it is necessary to perform detailed comparisons between models and observations to assess whether models are indeed biased or whether discrepancies are more apparent than real (Kerminen et al., 2012). Quantifying survival probability and $\mathrm{CCN}$ formation efficacy can be done with both ambient data and modeling output. Here we build upon previous studies to show how size distribution observations can be used to infer $\mathrm{CCN}$ formation rates from nucleation on a long-term (one year) basis. The result is an observational constraint on the overall $\mathrm{CCN}$ formation from singleday nucleation and growth events. In this paper, we analyze ambient measurements and model output and calculate relevant nucleation metrics such as the nucleation rate, growth rate, condensation and coagulation sink, survival probably, and $\mathrm{CCN}$ formation. We present an evaluation of model results by comparing to the nucleation metrics calculated for ambient measurements. We recommend that future modeling studies of nucleation and $\mathrm{CCN}$ use these similar metrics to allow for straightforward comparisons between models and with observations. Uncertainties in nucleation theories and growth mechanisms dictate that global aerosol microphysics models must be evaluated against nucleation-relevant observations in order to be used in a predictive capacity.

\section{Models and analysis}

\subsection{GEOS-Chem}

The Goddard Earth Observing System global chemical transport model (GEOS-Chem) version 8.2.2 is used for this study (Bey et al., 2001; http://geos-chem.org/). The version of GEOS meteorological fields used was either GEOS-3 or GEOS-5, as required by the simulation period (Table 1). In all simulations, $4^{\circ}$ latitude by $5^{\circ}$ longitude resolution is used with 30 vertical sigma-coordinate layers extending from the surface to $0.01 \mathrm{hPa}$. GEOS-Chem v8.2.2 contains all of the features described in Trivitayanurak et al. (2008) with the following updates. Anthropogenic emissions are treated with the Emissions Database for Global Atmospheric Research 
(EDGAR) inventory but are often overwritten by a number of regional inventories (Olivier et al., 1996). These regional inventories include Big Bend Regional Aerosol and Visibility Observational Study (BRAVO) emissions inventory for Mexico and southwestern USA, Criteria Air Contaminants (CAC) for anthropogenic emissions over Canada (http: //www.ec.gc.ca/inrp-npri/), the Cooperative Programme for Monitoring and Evaluation of the Long-range Transmission of Air Pollutants in Europe (EMEP), EPA National Emissions Inventory (NEI) for the United States (http://www.epa. gov/oar/data/neidb.html), and the Streets inventory for Asian emissions (Kuhns et al., 2003; Auvray and Bey, 2005; Streets et al., 2001). Biogenic emissions in the model follow the MEGAN database, and biomass burning emissions use the Global Fire Emissions Database version 2 (GFEDv2) (Van der Werf et al., 2005; Guenther et al., 2006). $\mathrm{NO}_{\mathrm{x}}$ emissions from aircraft, lightning, and soil are considered in the global model. Shipping $\mathrm{SO}_{\mathrm{x}}$ emissions are considered within EDGAR and EMEP.

\subsection{TwO-Moment Aerosol Sectional (TOMAS) algorithm}

Aerosol microphysics calculations are performed with the TOMAS algorithm, which is hosted by the GEOS-Chem global chemical transport model. TOMAS was introduced as a standard component of GEOS-Chem in version 8.2.2 and 8.3.1 and is available for download (www.geos-chem.org). Advantages of the TOMAS algorithm and GEOS-Chem implementation include the fact that all aerosol species have explicit, interactive microphysics and TOMAS conserves number concentrations allowing calculation of aerosol number budgets. Generally, we employ the work of Trivitayanurk et al. (2008) with the organic aerosol additions of Pierce et al. (2007), the dust additions of Lee et al. (2009), and the nucleation implementations of Pierce and Adams (2009a). TOMAS is a modular algorithm that contains codes to calculate the effects of nucleation, coagulation, condensation/evaporation, cloud processing, size-resolved dry and wet deposition, and emissions on the number and mass size distribution of aerosols (Adams and Seinfeld, 2002; Tzivion et al., 1987). The aerosols are split up into nine chemical species including sulfate, sea salt, hydrophilic and hydrophobic organic carbon, externally and internally mixed elemental carbon, mineral dust, ammonium, and aerosol water. Each component is tracked across 40 logarithmically spaced size sections or "bins" with a range of $1.1 \mathrm{~nm}$ to $10 \mu \mathrm{m}$. Size-resolved deposition, coagulation, condensation, and cloud processing are unchanged from Trivitayanurak et al. (2008). Primary sulfate aerosol emissions are $1 \%$ of anthropogenic $\mathrm{SO}_{2}$ emissions emissions and use the size distributions described in Adams and Seinfeld (2003). Sea salt emissions are treated in the same manner as in Trivitayanurak et al. (2008). Organic aerosols were not included in Trivitayanurak et al. (2008) but are included in the present work and described in the next section. Advection, chemistry, and deposition have remained largely unchanged from the work of Trivitayanurak et al. (2008), although periodic minor updates in both advection and chemistry (e.g., newer reaction rate constants and photolysis constants) have been implemented into successive versions of GEOS-Chem.

Activation to cloud condensation nuclei is based on Köhler theory (Raymond and Pandis, 2003), which is incorporated via look-up tables that take percent composition of sulfate, sea salt, organic carbon and insoluble material as inputs and yield critical activation diameters at various supersaturations as output. Below we highlight some recent additions to GEOS-Chem-TOMAS.

\subsubsection{Carbonaceous aerosol}

Carbonaceous aerosols are configured in a similar manner to Pierce et al. (2007). The aerosol is divided into four subcategories: externally mixed EC (elemental carbon), internally mixed EC, hydrophobic OC (organic carbon), and hydrophilic OC. The contributions of each of the categories to $\mathrm{CCN}$ activity is represented using the single, lumped, hygroscopicity parameter $(\kappa)$ of Petters and Kreidenweis (2007). We assume a constant OM: OC ratio of 1.8 for all emissions and for ambient organic aerosol (El-Zanan et al., 2005; Zhang et al., 2005). The effect of organic aerosol on surface tension depression (Facchini et al., 1999; Nenes et al., 2002) in activating cloud drops is not considered. The timescale for conversion of hydrophobic to hydrophilic aerosol was 1.5 days. Conversion from externally mixed to internally mixed EC uses this same timescale.

Secondary organic aerosol (SOA) is considered to be entirely nonvolatile and does not react or partition between the aerosol and gas phase. Instead, SOA production in TOMAS is calculated as $10 \%$ of global monoterpene emissions, resulting in approximately $19 \mathrm{Tg} \mathrm{yr}^{-1}$ of SOA. The SOA condenses to all particles based on their Fuchs surface area (Pandis et al., 1991). Although there is overwhelming evidence for the thermodynamic partitioning of semi-volatile organic aerosols (Donahue et al., 2006), the nonvolatile, kinetic condensation SOA treatment used here is simple and performed well in earlier nucleation studies that compared to observed aerosol number concentrations and growth rates (Riipinen et al., 2011; Pierce et al., 2011).

\subsubsection{Nucleation}

Several changes have been made to the treatment of nucleation in GEOS-Chem-TOMAS since Trivitayanurak et al. (2008). Gas-phase sulfuric acid concentrations are now calculated using a pseudo-steady state approach for each time step (Pierce and Adams, 2009a). Nucleation is treated using either ternary nucleation (Napari et al., 2002) with a $10^{-5}$ tuning factor or activation nucleation (Sihto et al., 2006) with an $A$ factor of $2 \times 10^{-6} \mathrm{~s}^{-1}$. We have chosen an $A$ in the 
range found to be most atmospherically applicable based on measurements in the continental boundary layer (Sihto et al., 2006, Riipinen et al., 2007), however results are somewhat sensitive to the $A$ factor choice within reasonable bounds (Spracklen et al., 2010). The lower boundary on the size distribution of $1.1 \mathrm{~nm}$ allows for explicit simulation of the dynamics of fresh nuclei. The model saves size distributions at $30 \mathrm{~min}$ time steps at each of the five locations for comparison against highly time resolved ambient measurements.

\subsection{Ambient measurements}

Table 1 outlines the five locations where we have obtained size distribution data; Pittsburgh, Hyytiälä, Atlanta, St. Louis, and San Pietro Capofiume (also referred to as Po Valley from this point forward). These locations span a range of conditions, making the set a good test for a global aerosol microphysics model. For instance, growth at Hyytiälä is dominated by organic condensation (Riipinen et al., 2011), whereas at Pittsburgh, sulfuric acid condensation is the leading mechanism for particle growth (Jung et al., 2010). Urban, polluted continental, and clean continental sites are represented, although the fact that 3 out of 5 sites are urban complicates comparison with a global model. At each of the sites, size distribution measurements were made for at least one continuous year with either a scanning mobility particle sizer (SMPS) or differential mobility particle sizer (DMPS). Sulfuric acid measurements were made at Hyytiälä using a chemical ionization mass spectrometer (CIMS) (Petäjä et al., 2008). Time resolution in the size distribution observations was typically finer than in the model output as all sites recorded measurements in no longer than 15 min intervals. Analysis of both the ambient measurements and model output used the same procedure for calculating nucleation relevant quantities (e.g., growth rates and survival probabilities) from size distribution data (see Sect. 2.5).

\subsection{Simulations}

Simulations were performed over a time period coinciding with the times that the observations were taken. This ability to perform near real time simulations is a strength of the assimilated meteorology employed by GEOS-Chem. Each of the years of comparison are listed in Table 1. For Hyytiälä, the year of comparison used is 2007. The Pittsburgh, Po Valley, Atlanta, and St. Louis measurement periods were all several years earlier ranging from 1999 to 2003 . For each location, two simulations were performed reflecting the two nucleation schemes tested: ternary nucleation (Napari et al., 2002) with a $10^{-5}$ tuning factor and activation nucleation (Sihto et al., 2006) in the boundary layer coupled with binary nucleation (Vehkamaki et al., 2004) elsewhere. Thus, in total we ran 10 simulations for 14 months, which includes 2 months of model spin-up. For each model grid cell corresponding to the location of the measurements, number size distribution and sulfuric acid concentration output was saved for analysis and comparison with measurements. We do not interpolate number size distribution values within the given grid cell. The horizontal resolution used here is a challenge for comparisons with observations, and results will generally show better comparisons to rural observations. This should be addressed in the future with improved model resolution, but additional long-term data sets of aerosol size distributions in rural locations are needed.

\subsection{Nuclei fate analysis and $\mathrm{CCN}$ formation potential}

To calculate nucleation rates and infer the fates of nucleated particles, we have modified a series of nucleation dynamics codes for Hyytiälä data referenced in Dal Maso et al. (2005). These codes, which have been modified slightly for use with TOMAS output and other ambient datasets, calculate the following: formation rates of $3 \mathrm{~nm}$ particles, diameter growth rates, condensational and coagulational sinks, absolute number concentration, particle survival probability, formation rates of 50 and $100 \mathrm{~nm}$ particles, and steadystate cloud condensation nuclei concentrations attributable to nucleation and growth events. The original Dal Maso et al. (2005) nucleation code relied mostly on visual inspection of the nucleation events to determine start points and end points of the growing diameter trajectory. We have modified the code such that the ambiguity of visual determination is eliminated as the start and end points are now automated. The following sections outline the method of calculation for each of these metrics.

\subsubsection{Frequency of events}

For nucleation event frequency, our methods are similar to those outlined in Dal Maso et al. (2005). The evolution of the particle size distribution over the course of the day ("banana plot", Fig. 2) reveals some features that we use to identify nucleation events. First, a distinctly new nucleation mode $(1-25 \mathrm{~nm})$ of particles must appear in the size distribution. Secondly, the new mode must last at least $2 \mathrm{~h}$ and show signs of growth. Figure 2 shows example measured and modeled nucleation events. For example, at about 14:00 UTC at Pittsburgh, PA, on 16 April 2002, a large number of $3 \mathrm{~nm}$ particles were measured to appear and subsequently grow as evidenced by the red contours (black dashed line) moving up in both diameter space and time.

\subsubsection{Formation rate and growth rate}

The formation rate (or nucleation rate) of $3 \mathrm{~nm}$ particles $\left(J_{3}\right)$ is calculated from the time derivative of nucleation mode number concentration $\left(N_{3-25}\right)$ with a coagulation correction $\left(F_{\text {coag }}\right)$ representing scavenging of small particles by pre-existing aerosol (Eq. 1) and a condensation correction $\left(F_{\text {growth }}\right)$ accounting for growth of particles out of the size range by condensation. Although the flux of particles out of 

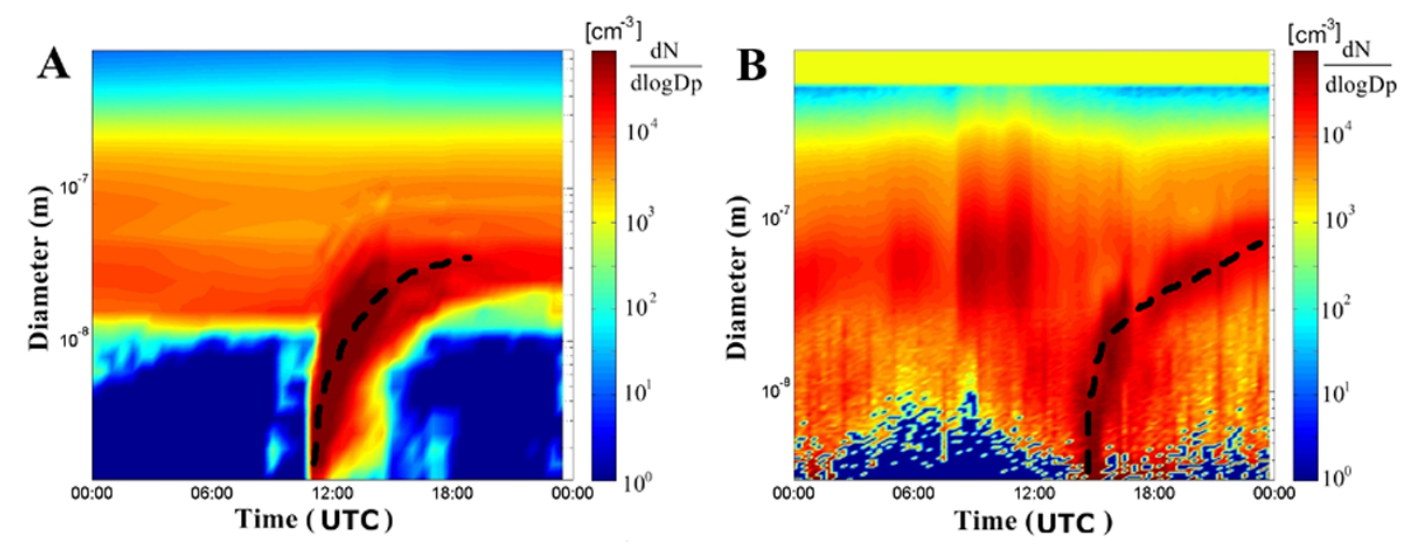

Fig. 2. Sample new particle formation events in the model with ternary nucleation $\left(10^{-5}\right.$ tuning factor) and measurements at Pittsburgh. Contours represent values of the size distribution function plotted against particle diameter in $\mathrm{m}$ (ordinate) and time in UTC (abscissa). Dashed line represents the diameter growth trajectory (A) Pittsburgh, PA, USA, modeled 16 April 2002 (B) Pittsburgh, measured, 16 April 2002.

the size range $\left(F_{\text {growth }}\right)$ term is often neglected because particles may not grow beyond $25 \mathrm{~nm}$ during the nucleation burst (Dal Maso et al., 2005), we have included it here. The values of $J_{3}$ are averaged over $24 \mathrm{~h}$ periods for consistency in comparisons (more details in Sect. 2.5.4). Therefore, all else being equal, a longer nucleation event will result in a higher average $J_{3}$ value for that day compared to a shorter event. This facilitates subsequent analysis of the particle number budget and avoids the need for a semi-arbitrary determination of precisely when the nucleation event began and ended:

$J_{3}=\frac{\mathrm{d} N_{3-25}}{\mathrm{~d} t}+F_{\text {coag }}+F_{\text {growth }}$

The size distribution function is integrated over the 3$25 \mathrm{~nm}$ size range to get the absolute number concentrations, which vary with time. The coagulation correction is the product of the 3-25 nm number concentration and the corresponding coagulation sink (described in Sect. 2.5.3) for a particular larger size, integrated across all particles larger than $25 \mathrm{~nm}$. Zhang et al. (2010a) and Zhang et al. (2010b) compared observed nucleation rates at Atlanta to various model parameterizations in a similar manner as we have summarized here.

Diameter growth rates (GR) are calculated by considering the peak of the size distribution at 3 and $25 \mathrm{~nm}$. We make a linear fit to the maximum value of the size distribution as it varies over time. The slope of the fitted line is the diameter growth rate. An additional growth rate is calculated for the $25-100$ and $25-50 \mathrm{~nm}$ size ranges for purposes of the condensational growth timescale calculation, explained in Sect. 2.5.3. Since the growth rate does not vary much within the nucleation or Aitken mode for the modeled and measured nucleation events, this assumption is justified.

\subsubsection{Coagulation and condensation sinks}

Calculation of coagulational and condensational growth is adapted from the Probability of Ultrafine Growth (PUG) model, introduced by Pierce and Adams (2007). Loss of small nuclei by collisions with larger, pre-existing aerosol is the major pathway preventing growth of nucleated particles to Aitken mode and larger sizes. The frequency of coagulational loss, CoagS $\left(\mathrm{s}^{-1}\right)$, of particles of size $i$ to a larger size $j$ is dependent on a coagulation coefficient $\left(K_{i j}\right)$ and the number concentration in the larger size range, $N_{j}$ (Eq. 2). Coagulation of particles of the same size is represented by the first term in Eq. 2. The CoagS term is both size and time dependent. In our calculations, we set the initial size to either 1 or $3 \mathrm{~nm}$ (the lower size cutoff of the model and measurements, respectively) and calculate coagulation coefficients for all particles larger than size $i$. The coagulation coefficient is based on the Fuchs equation (Seinfeld and Pandis, 2006):

$$
\operatorname{CoagS}_{i}=\frac{1}{2} K_{i i} N_{i}+\sum_{j=i+1}^{\max } K_{i j} N_{j} .
$$

The condensation sink describes the first-order rate of uptake of sulfuric acid or other condensable vapors to aerosols (Eq. 3). In the kinetic regime, the condensation sink is proportional to surface area and is proportional to particle diameter in the continuum regime:

$$
\mathrm{CS}=2 \pi D \sum_{i=1}^{\max } \beta_{i} D_{p i} N_{i} .
$$

In Eq. (3), the condensation sink (CS) is calculated from the gas-phase diffusion constant $(D)$, particle diameter in size bin $i\left(D_{p i}\right)$, number concentration in size $i\left(N_{i}\right)$, and the transition regime (connecting the kinetic and continuum regimes) correction factor $\beta_{i}$, which is dependent on the 
Knudsen number (Seinfeld and Pandis, 2006). The condensational growth timescale, not to be confused with condensation sink, is the time it takes for a particle to grow to a size of interest. The coagulation timescale is the inverse of the coagulation sink for a given size range. These two timescales (Eqs. 4 and 5) are required for the survival probability calculation (Sect. 2.5.4). In physical terms, the timescales represent the amount of time it takes for particles in size range $k$ to grow or be lost to larger sizes:

$\tau_{k, k+1}^{\mathrm{cond}}=\frac{D_{p, k+1}-D_{p, k}}{\mathrm{GR}_{k, k+1}}$,

$$
\tau_{k}^{\text {coag }}=\frac{1}{\frac{1}{2} K\left(D_{p, k}, D_{p, k}\right) N_{k}+\sum_{j=k+1}^{k_{\max }} K\left(D_{p, k}, D_{p, j}\right) N_{j}} .
$$

In Eq. (5), similar to Eq. 2, the first term in the denominator represents self-coagulation of particles in the same size bin. The second term represents coagulation with particles in larger size bins, up to the model or measurement maximum size, $k_{\max }$.

\subsubsection{Survival probability and CCN formation}

We define survival probability as the ratio of particle fluxes at the initial point of growth (typically $J_{3}$ ) and the CCNrelevant size or endpoint of growth $\left(J_{n}\right.$, with $n=50$ or $100 \mathrm{~nm}$ typically). Figure 1 highlights the sources and sinks of particles throughout nuclei growth. Within our analysis, survival probability (SP) is calculated using two intermediate calculations of coagulational loss and condensational growth timescales. Both timescales (Eqs. 4, 5), are calculated for nucleation mode as it grows with time. We do not consider the loss due to wet deposition, which typically occurs at much slower timescales than coagulation (days versus hours). Additionally, if wet scavenging did happen, it would likely be noticeable in the size distribution evolution plots and classified as a non-event. Similar to Kuang et al. (2009), we calculated a single survival probability for each nucleation event corresponding to the trajectory of particles following the maximum value of the nucleation mode (dashed line in Fig. 2). Thus, for each time step (30 $\mathrm{min}$ for the model, shorter for measurements) the instantaneous coagulational loss and condensational growth timescales are calculated. The overall survival probability, shown in Eq. (6), from size $m$ to $n$ (here, $3-100$ or $3-50 \mathrm{~nm}$ ), is calculated as the product of individual probabilities across smaller size ranges, represented by the exponential term inside of the product in Eq. (6). In physical terms, this method calculates the probability of nuclei growth from one discrete size (or section for model output) to the next largest size. Taking the product of these individual probabilities yields a survival probability from fresh nuclei to CCN-relevant sizes. When calculating survival probabilities from observations, using Eq. (6), we take the coagulational and condensational timescales from Eqs. (4) and (5), in which the growth rate is inferred from observations, the size-resolved number concentrations are also from observations, and coagulation coefficients are calculated from theory. Therefore, although some theoretical calculations are required, the key inputs related to condensational growth and coagulational scavenging, are based on observations. An analogous procedure is used for calculating survival probabilities from model nucleation and growth events:

$\mathrm{SP}_{m, n}=\prod_{k=m}^{n-1} \exp \left(-\frac{\tau_{k, k+1}^{\text {cond }}}{\tau_{k}^{\text {coag }}}\right)$.

The formation rate of $100 \mathrm{~nm}$ particles $\left(J_{100}\right)$ is calculated as the $3 \mathrm{~nm}$ formation rate multiplied by the survival probability from 3 to $100 \mathrm{~nm}$ (Eq. 7). Likewise, $J_{50}$ is calculated as $J_{3}$ multiplied by the survival probability to $50 \mathrm{~nm}$. These two particle sizes are within the range of typical activation diameters for $\mathrm{CCN}$ concentrations. Although this method does not consider particle composition, under typical supersaturations, many particles of 50 or $100 \mathrm{~nm}$ in size will activate to CCN (Seinfeld and Pandis, 2005). For atmospheric conditions most typical for the indirect effect, stratiform clouds and mixed inorganic and organic particles, the $100 \mathrm{~nm}$ size is probably the most appropriate CCN surrogate (Seinfeld and Pandis, 2005). However, because few nucleation and growth events reach the $100 \mathrm{~nm}$ cutoff ( $n=100 \mathrm{in}$ Eq. 7 ) on the same day, an analysis focusing on the $100 \mathrm{~nm}$ cutoff necessarily excludes a large number of useful observations. Therefore, we also compare survival results for $50 \mathrm{~nm}(n=50)$ between model and observations, which is still CCN relevant and includes a larger number of events (see Table 5):

$J_{n}=\mathrm{SP}_{3-n} J_{3}$.

For the purposes of model-measurement comparison, we do not consider growth of particles beyond the nucleation day. There are a few reasons for this. First, air masses often shift over a given location after one day, making it difficult to make model-measurement comparisons after the first day. Secondly, if the model compares well to the first day of nucleation, there is no reason to expect the performance to get worse if multiple days are considered. Finally, we acknowledge that for the goal of defining the $\mathrm{CCN}$ budget contribution by nucleation, multiday growth is more important. We leave that for future work and focus on model-measurement comparison here, where the use of single day estimates of nucleation metrics is justifiable.

Because of large uncertainty and a lack of constraints on $\mathrm{CCN}$ lifetimes in the observations, it is difficult to convert our $\mathrm{CCN}$ formation results into absolute $\mathrm{CCN}$ concentrations. In the real atmosphere, a reasonable range might be between one and seven days (Twomey and Wojciechowski, 1969). Clearly, this factor of 7 can be the determining factor 


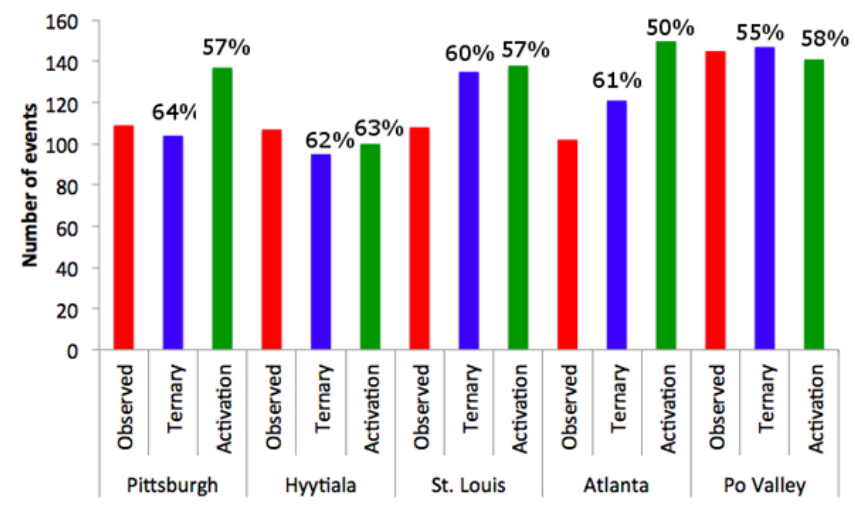

Fig. 3. New particle formation event frequency for one year across the five datasets and simulations. Observations are in red, ternary with a $10^{-5}$ tuning factor nucleation simulation is in blue, and activation nucleation simulation is in green. Numbers above the ternary and activation columns represent the percentage of matching events or non-events for the two model cases compared to observations.

for the $\mathrm{CCN}$ concentrations from nucleation and the corresponding fractional contribution to total CCN. We therefore leave our results as $\mathrm{CCN}$ formation rates as calculated by Eq. (7). There are also uncertainties in the calculations of the modeled and measured growth rate, nucleation rates, survival probabilities, etc. However, since we apply the same calculations under the same assumptions for the model output and the observations, our model-measurement comparison results should be largely unaffected.

\section{Results}

Figure 2 shows sample boundary layer nucleation events in the ternary nucleation model and in the ambient observations. At Pittsburgh on 16 April, strong growth to $80 \mathrm{~nm}$ is seen in the observations and in the ternary model. Figures 3 and 4 show results for new particle formation event frequency, both on a yearly and monthly basis. Figures 5-9 are cumulative distribution functions of nucleation and growth metrics from the year of simulations and observations separated by each site. The quantities chosen for model-measurement comparison are formation rate $\left(J_{3}\right)$, growth rate (GR), survival probability from $3-50$ and $100 \mathrm{~nm}$ $\left(\mathrm{SP}_{50}\right.$ and $\mathrm{SP}_{100}$, respectively), and 50 and $100 \mathrm{~nm}$ particle formation rates $\left(J_{50}\right.$ and $\left.J_{100}\right)$. Each point in the CDF (cumulative distribution function) of a given nucleation metric represents one nucleation event (or one day) for that specific metric. These plots include only data and model output from the subset of days that are categorized as nucleation events according to the methodology described in Sect. 2.5.1. For the $\mathrm{CCN}$ formation rate and survival probability panels of the CDF figures, days where the nucleation mode does not grow to the particular cutoff size $(50$ or $100 \mathrm{~nm})$ are not included in the figure. The number of these days for each site in the model and the observations can be seen in Table 5 . All formation rates $\left(J_{3}, \mathrm{~J}_{50}\right.$, and $\left.\mathrm{J}_{100}\right)$ are averaged over $24 \mathrm{~h}$, as is explained in Sect. 2.5.4. They are, therefore, somewhat lower than instantaneous rates that may be more familiar to some researchers. For Hyytiälä, where additional measurements are available, Figs. 10 and 11 add a few more metrics such as condensation sink, sulfuric acid concentrations, and speciated growth rates. Figure 12 summarizes the biases in each nucleation metric for each site for each nucleation theory, ternary (with a $10^{-5}$ tuning factor) and activation.

\subsection{Overview of model-measurement comparison results by location}

At each site, event frequency (Fig. 3) is predicted well by both the ternary and activation model cases. The bars represent number of events and the percentages over the bars represent the number of specific days that are correctly modeled as either events or non-events. Among the five stations, the scaled ternary simulation misses the exact number of events over the year by as few as two days and as many as 27 days. The ternary simulation underpredicts at Pittsburgh and Hyytiälä but overpredicts at the other three sites. The largest discrepancies come in the overprediction at St. Louis and Atlanta. These two locations are generally "urban background" sites that are difficult for the coarse-resolution model to represent accurately. Despite these difficulties, the model is able to get within 25 and $18 \%$ of the observed frequency of events at St. Louis and Atlanta, respectively. The activation simulation tends to be more inaccurate than the ternary simulation (off by seven to 75 days across the five stations) and is also mixed in its underprediction and overprediction. The biggest model error (75 days overprediction) comes at Atlanta, where the activation nucleation theory performs much worse than the scaled ternary simulation.

It is encouraging that the model can predict accurately the number of nucleation days in one year, but the model shows only limited skill in correctly forecasting whether nucleation occurs or not on any given day. The numbers above the bars in Fig. 3 show the percentage of exact days that are correctly modeled as either events or non-events. Again, the model does best at Pittsburgh and Hyytiälä, where about 64 and $62 \%$ out of the 365 days in the year are accurately modeled as events or non-events. Thus, there is significant room for improvement in individual day comparisons in the model. Besides the accuracy of the nucleation parameterization itself, a host of related variables and processes have to be predicted correctly to get each day right: precipitation, cloud cover, and the emissions and transport of precursor species such as sulfur dioxide and ammonia, for ternary nucleation. Future work should investigate whether the limited skill in predicting day-to-day variability results primarily from weaknesses in the nucleation parameterizations themselves or from other processes controlling precursor concentrations. 

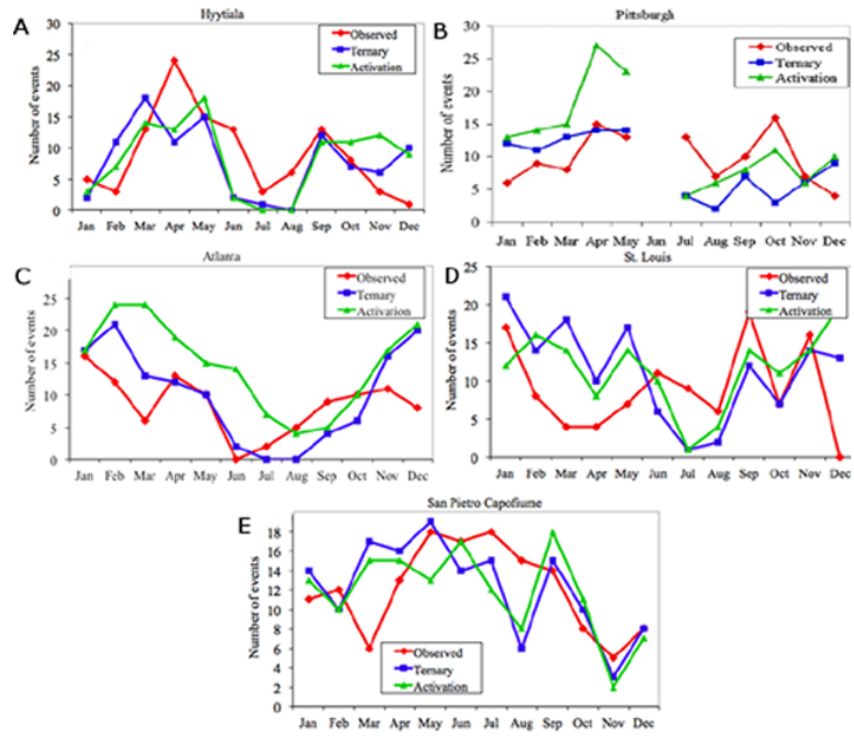

Fig. 4. New particle formation event frequency as a function of month for the five datasets and simulations. Observations are in red, ternary nucleation model (with a $10^{-5}$ tuning factor) is in blue, and activation nucleation is in green. Data is missing in June at PGH (Pittsburgh) due to SMPS malfunction.

Figure 4 shows the seasonal breakdown of events on a month by month basis. In general, the model shows mixed performance in following the seasonal trend, with Hyytiälä showing the closest correlation $(R=0.83$, ternary). The model performs better here than any other site, which may be because the activation nucleation parameterization was developed with data from Hyytiälä, although the scaled ternary formulation also performs well here. Additionally, spatial homogeneity and the lack of strong local sources at Hyytiälä also probably play a role. For models with coarse spatial resolution, spatially homogenous sites such as Hyytiälä make for ideal comparisons. Another possibility is the use of the more recent GEOS-5 meteorological fields at Hyytiälä, which were not used at any of the other sites. The model underpredicts nucleation days for both ternary and activation in April at Hyytiälä, most likely due to sulfuric acid concentration underpredictions (see Fig. 10). At Pittsburgh ( $R=0.23$, ternary), events are overpredicted in the early winter months (January-March), but underpredicted in the fall months (September-November). Overprediction in the early winter months appears to be a common theme among other locations as well. The model does quite well in the spring and summer months, with near exact prediction by the ternary simulation in April and May at Pittsburgh. Results for June in Pittsburgh are missing because of instrument failure and data loss. St. Louis and Atlanta show surprisingly similar behavior in the model; nucleation events are at maximum in the winter and minimum during the summer months. This behavior appears to be occurring at other locations within the model as well and is at least somewhat
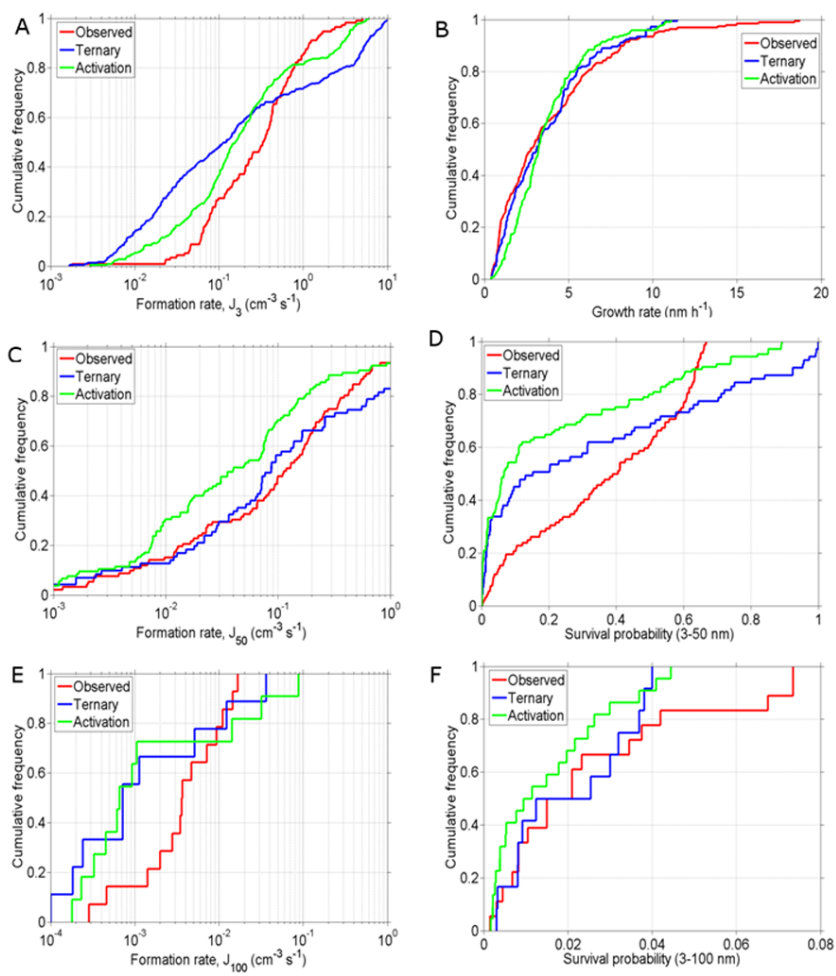

Fig. 5. Cumulative distribution function (CDF) of modeled and measured nucleation metrics at PGH. Twenty-four hour averaged nucleation rate $\left(J_{3}\right)$ is shown in panel (A), growth rate for eventlengths in panel $(\mathbf{B}), 50 \mathrm{~nm}$ particle formation rate $\left(J_{50}\right)$ in panel (C), survival probability to $50 \mathrm{~nm}\left(\mathrm{SP}_{3}-50\right)$ in (D), $100 \mathrm{~nm}$ particle formation rate $\left(J_{100}\right)$ in panel $(\mathbf{E})$, and survival probability to $100 \mathrm{~nm}\left(\mathrm{SP}_{3-100}\right)$ in panel $(\mathbf{F})$. Descriptive statistics for these distributions can be found in Tables 2 and 3 .

representative of observed seasonal trends at Atlanta and St. Louis ( $\mathrm{R} \sim 0.6$ for both, ternary). Although one might expect nucleation primarily in the summertime due to enhanced photochemical activity and greater availability of biogenic VOC (volatile organic compounds) precursors, colder temperatures favor nucleation in the wintertime (Dal Maso et al., 2005). At Hyytiälä, Pittsburgh, and Po Valley the strong nucleation in spring and fall may result from the balance between these two factors. Seasonal variations in prevailing wind direction, boundary layer height and cloudiness may also be important in some locations (Jaatinen et al., 2009). The observed seasonal cycle of nucleation is an important test of the models that requires further attention.

Figures 5-9 show the modeled and measured comparisons for each of the nucleation and growth metrics. Each figure contains comparisons for one year of nucleation events at a specific location: Pittsburgh, Hyytiälä, Atlanta, St. Louis, and Po Valley. Tables 2 and 3 show the median and mean values of each metric. Table 4 shows mean, median, and log-mean normalized biases (LMNB, the average number of ordersof-magnitude error) for additional modeled and measured 

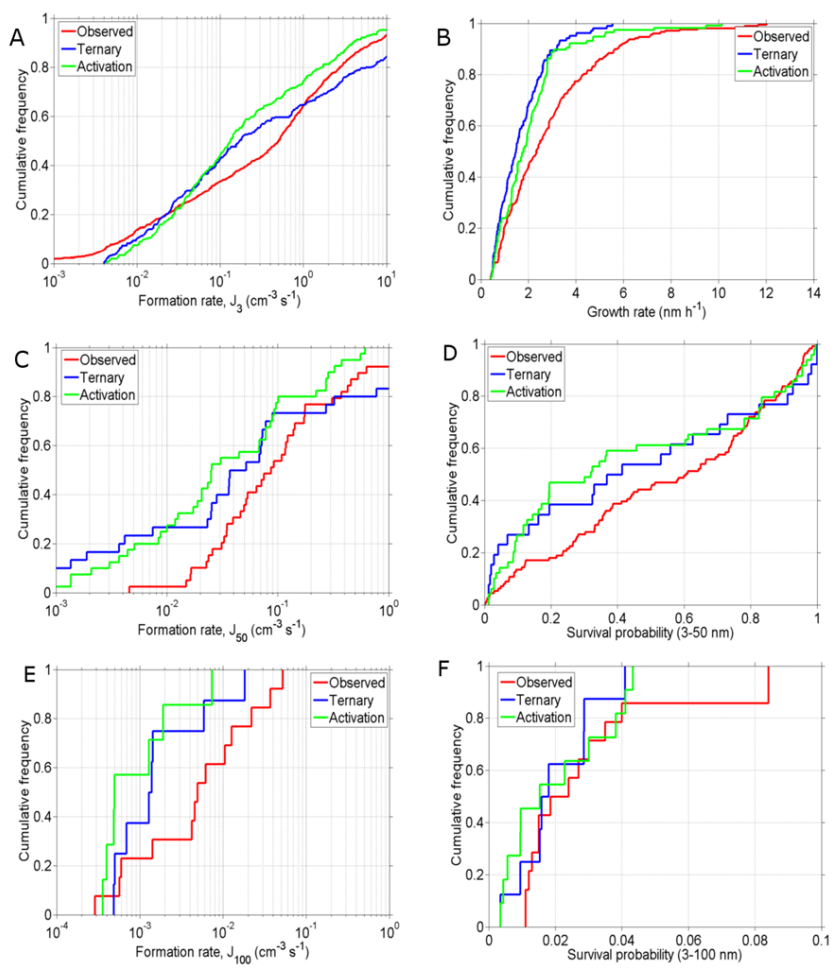

Fig. 6. Same as in Fig. 5, for modeled and measured nucleation metrics at Hyytiälä (HYY).

quantities $\left(\left[\mathrm{H}_{2} \mathrm{SO}_{4}\right], \mathrm{CS}, \mathrm{CoagS}\right)$ at Hyytiälä. Table 5 shows total number of events at each site as well as the subset of those events in which particles grew to the cutoff diameters of 50 and $100 \mathrm{~nm}$.

As an example of the model-measurement comparison cumulative distribution functions (CDF), Fig. 5 shows results for Pittsburgh. Cumulative frequency is plotted against the specific nucleation metric for the observations, scaled ternary simulation, and activation simulation. Overall, both the ternary and activation model agree well with observations at Pittsburgh (red trace in Fig. 5), as evidenced by the tight agreement in the CDFs and values of means and medians (Tables 2,3). For example, the median growth rate of $2.8 \mathrm{~nm} \mathrm{~h}^{-1}$ at Pittsburgh is accurately predicted by the ternary model $\left(3.1 \mathrm{~nm} \mathrm{~h}^{-1}\right)$ and activation $\left(3.2 \mathrm{~nm} \mathrm{~h}^{-1}\right)$. Median $3 \mathrm{~nm}$ formation rates $\left(J_{3}\right)$ are underpredicted by almost a factor of 3 in the scaled ternary simulation but only by $22 \%$ in the activation simulation. The accurate survival probability $\left(\mathrm{SP}_{100}\right)$ prediction at Pittsburgh (Fig. 5f) benefits from an underprediction in coagulation frequency, although the model fails to capture the strongest survival events. This is consistent with the tail of the growth rate CDF (Fig. 5b), in which a few events reach upwards of $18 \mathrm{~nm} \mathrm{~h}^{-1}$ in the observations but never surpass $\sim 12 \mathrm{~nm} \mathrm{~h}^{-1}$ in the two model scenarios. The modeled formation rates of CCN-sized particles (Fig. 5c, e) are generally in agreement with the measurements. However, some deviations exist, particularly with the activation
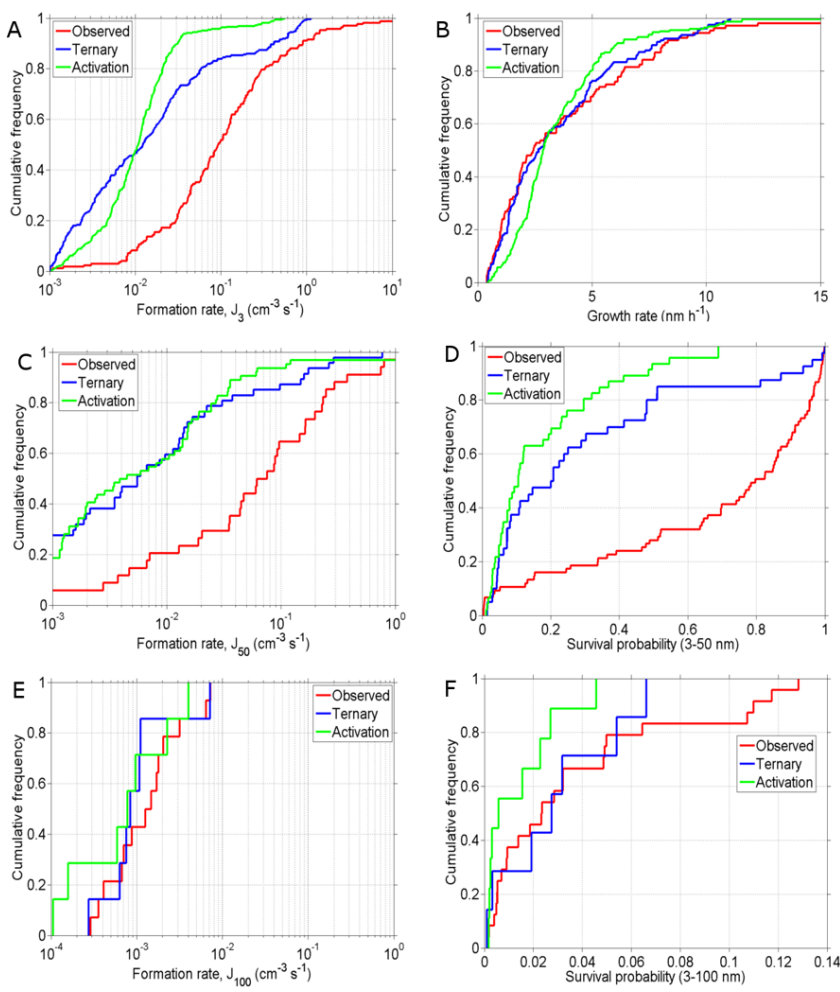

Fig. 7. Same as in Fig. 5, for modeled and measured nucleation metrics at Atlanta (ATL).

and binary coupled nucleation simulation, which fails to predict the observed $50 \mathrm{~nm}$ formation rate $\left(J_{50}\right)$ throughout most of the distribution. Additionally, both mechanisms fail at predictions of $100 \mathrm{~nm}$ formation rates $\left(J_{100}\right)$ at values of about $0.005 \mathrm{~cm}^{-3} \mathrm{~s}^{-1}$ and lower (Fig. 5e). It should be noted, however, that these are among the weaker nucleation and growth events that are being underpredicted. For values larger than $0.005 \mathrm{~cm}^{-3} \mathrm{~s}^{-1}$, nucleation will contribute appreciable amounts of $\mathrm{CCN}$ to the total budget, and the model largely is accurate in this regime.

Figures 6-9 show the comparisons of the same metrics at Hyytiälä, Atlanta, St. Louis, and the Po Valley. One particularly interesting result is the modeled and measured growth rates at Hyytiälä (Fig. 6b). Despite a relatively simple treatment of SOA in the global model, growth rates at the organic-dominated location are not severely underpredicted by TOMAS with either the ternary or activation nucleation schemes. Mean modeled values are 1.7 and $2.0 \mathrm{~nm} \mathrm{~h}^{-1}$ compared to $2.8 \mathrm{~nm} \mathrm{~h}^{-1}$ observed. Although we are on the lower end of expected global SOA formation $\left(19 \mathrm{Tg} \mathrm{yr}^{-1}\right)$, the completely nonvolatile treatment of organics favors condensation onto the freshly nucleated particles (Riipinen et al., 2011). These inaccuracies may offset one another and result in modeled growth rates closer to observed. The growth rate in the model is driven mainly by organic condensation and not by sulfuric acid (Fig. 11). Additionally, the good 
Table 2. Median values for each metric for each site. $\mathrm{O}=$ observed, $\mathrm{T}=$ ternary simulation, $\mathrm{A}=$ activation simulation.

\begin{tabular}{|c|c|c|c|c|c|c|c|c|c|c|c|c|c|c|c|}
\hline & \multicolumn{3}{|c|}{ Pittsburgh } & \multicolumn{3}{|c|}{ Hyytiälä } & \multicolumn{3}{|c|}{ Atlanta } & \multicolumn{3}{|c|}{ St. Louis } & \multicolumn{3}{|c|}{ Po Valley } \\
\hline & $\mathrm{O}$ & $\mathrm{T}$ & A & $\mathrm{O}$ & $\mathrm{T}$ & A & $\mathrm{O}$ & $\mathrm{T}$ & A & $\mathrm{O}$ & $\mathrm{T}$ & A & $\mathrm{O}$ & $\mathrm{T}$ & A \\
\hline$J_{3}\left(\mathrm{~cm}^{-3} \mathrm{~s}^{-1}\right)$ & 0.32 & 0.12 & 0.16 & 0.5 & 0.17 & 0.13 & 0.09 & 0.01 & 0.01 & 2.4 & 0.8 & 0.6 & 0.55 & 1.9 & 0.98 \\
\hline $\mathrm{GR}\left(\mathrm{nm} \mathrm{h}^{-1}\right)$ & 2.8 & 3.1 & 3.2 & 2.8 & 1.5 & 1.8 & 2.4 & 2.6 & 2.8 & 2.8 & 3.1 & 3.5 & 5.8 & 4.6 & 5.8 \\
\hline $\mathrm{SP}_{50}$ & 40 & 15 & 7 & 61 & 39 & 42 & 80 & 20 & 10 & 42 & 50 & 21 & 31 & 23 & 20 \\
\hline$J_{50}\left(\mathrm{~cm}^{-3} \mathrm{~s}^{-1}\right)$ & 0.1 & 0.09 & 0.04 & 0.089 & 0.044 & 0.025 & 0.05 & 0.006 & 0.004 & 0.45 & 0.2 & 0.12 & 0.16 & 0.12 & 0.11 \\
\hline $\mathrm{SP}_{100}(\%)$ & 1.7 & 1.7 & 1.1 & 1.8 & 1.7 & 1.7 & 2.3 & 1.4 & 0.6 & 1.1 & 5.5 & 2.1 & 4 & 2.5 & 2.4 \\
\hline$J_{100}\left(\mathrm{~cm}^{-3} \mathrm{~s}^{-1}\right)$ & 0.0037 & 0.001 & 0.0007 & 0.004 & 0.02 & 0.013 & 0.0008 & 0.0007 & 0.0009 & 0.009 & 0.004 & 0.002 & 0.18 & 0.047 & 0.045 \\
\hline
\end{tabular}

Table 3. Mean values for each metric for each site. $\mathrm{O}=$ observed, $\mathrm{T}=$ ternary simulation, $\mathrm{A}=$ activation simulation.

\begin{tabular}{|c|c|c|c|c|c|c|c|c|c|c|c|c|c|c|c|}
\hline & \multicolumn{3}{|c|}{ Pittsburgh } & \multicolumn{3}{|c|}{ Hyytiälä } & \multicolumn{3}{|c|}{ Atlanta } & \multicolumn{3}{|c|}{ St. Louis } & \multicolumn{3}{|c|}{ Po Valley } \\
\hline & $\mathrm{O}$ & $\mathrm{T}$ & A & $\mathrm{O}$ & $\mathrm{T}$ & A & $\mathrm{O}$ & $\mathrm{T}$ & A & $\mathrm{O}$ & $\mathrm{T}$ & A & $\mathrm{O}$ & $\mathrm{T}$ & A \\
\hline$J_{3}\left(\mathrm{~cm}^{-3} \mathrm{~s}^{-1}\right)$ & 0.58 & 1.5 & 0.71 & 2.5 & 5.2 & 1.6 & 0.69 & 0.10 & 0.03 & 8.7 & 10.6 & 2.3 & 6.3 & 2.9 & 3.4 \\
\hline $\mathrm{GR}\left(\mathrm{nm} \mathrm{h}^{-1}\right)$ & 3.9 & 3.7 & 3.7 & 2.8 & 1.7 & 2.0 & 3.8 & 3.5 & 3.6 & 4.2 & 3.5 & 4.7 & 6.9 & 5.1 & 6.1 \\
\hline $\mathrm{SP}_{50}$ & 37 & 33 & 22 & 55 & 46 & 43 & 67 & 30 & 18 & 46 & 47 & 33 & 34 & 27 & 30 \\
\hline$J_{50}\left(\mathrm{~cm}^{-3} \mathrm{~s}^{-1}\right)$ & 0.11 & 0.034 & 0.011 & 0.23 & 0.82 & 0.1 & 0.177 & 0.048 & 0.071 & 1.6 & 1.2 & 0.3 & 0.39 & 1.7 & 1.0 \\
\hline $\mathrm{SP}_{100}(\%)$ & 2.4 & 1.8 & 1.6 & 2.6 & 2.5 & 2.2 & 3.7 & 2 & 1.2 & 1.8 & 4.8 & 3.3 & 4.4 & 3.1 & 3.8 \\
\hline$J_{100}\left(\mathrm{~cm}^{-3} \mathrm{~s}^{-1}\right)$ & 0.006 & 0.009 & 0.004 & 0.021 & 0.011 & 0.002 & 0.006 & 0.004 & 0.002 & 0.046 & 0.024 & 0.006 & 0.34 & 0.66 & 0.4 \\
\hline
\end{tabular}
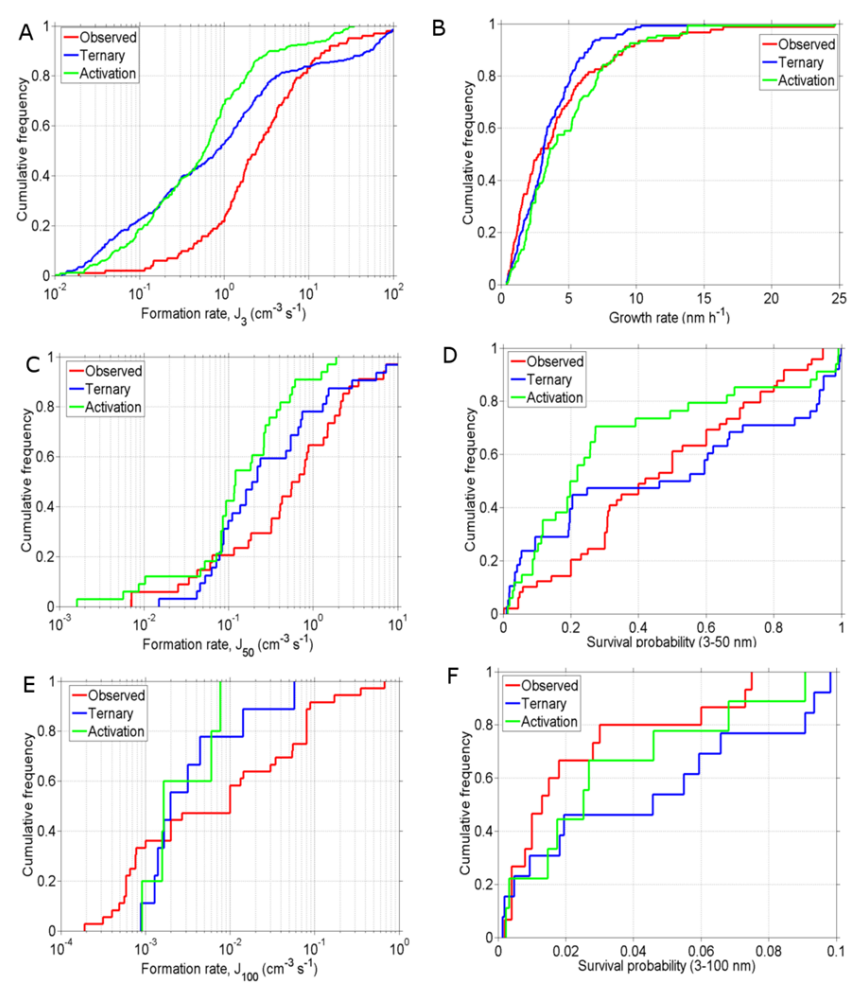

Fig. 8. Same as in Fig. 5, for modeled and measured nucleation metrics at St. Louis (STL).

model performance at Hyytiälä may be because it is a biogenic SOA dominated site, which is probably better represented in the global model when compared to anthropogenic SOA. Sect. 3.3 has additional comments on the speciated growth rate results, summarized for all of the five locations in Fig. 11.

In the comparisons for Atlanta in Fig. 7, we see worse model-measurement agreement than at Hyytiälä or Pittsburgh, particularly in the formation rates in panels $7 \mathrm{a}$ and $\mathrm{c}$. Formation rates of $100 \mathrm{~nm}$ particles are underpredicted by up to a factor of 5 and the discrepancy is similar for 3 and $50 \mathrm{~nm}$ formation. Figure 8 shows that comparisons at St. Louis are also worse than Hyytiälä or Pittsburgh for most metrics, especially the formation rate comparisons (Fig. 8c, e) which are generally underpredicted by the model by as much as a factor of 2. Finally, Fig. 9 (Po Valley) has some of the highest observed growth rates, and both nucleation simulations in the model capture this well (Fig. 9b). Accordingly, this site is also on the high end of survival probability and $100 \mathrm{~nm}$ formation rate $\left(J_{100}\right)$. This is consistent with Laaksonen et al. (2005), who found fast growth, high survival and high $\mathrm{CCN}$ formation at San Pietro Capofiume, Italy (Po Valley).

\subsection{Sulfuric acid, condensation sink, and coagulation sink}

Sulfuric acid measurements were available at Hyytiälä, and the comparison with model values is shown in Fig. 10a along with condensation sink (Fig. 10b) and coagulation sink (Fig. 10c). Table 4 shows summary statistics for these extra nucleation metrics. Only daily maximum sulfuric acid values are plotted in Fig. 10a. Included are both nucleation event and non-event days in all three plots. Generally, sulfuric acid is accurately predicted in the ternary and activation model as the median values agree within about $40 \%$. However, for the concentrations characteristic of nucleation events (approaching $10^{6} \mathrm{~mol} \mathrm{~cm}^{-3}$ and larger), both model scenarios 
Table 4. Mean, median, and bias values for three nucleation metrics specific to Hyytiälä (due to data availability). $\mathrm{O}=$ observed, $\mathrm{T}=$ ternary simulation, $\mathrm{A}=$ activation simulation.

\begin{tabular}{lrrrrrrrrrr}
\hline & \multicolumn{2}{c}{$\left[\mathrm{H}_{2} \mathrm{SO}_{4}\right]\left(10^{5} \mathrm{molec} \mathrm{cm}^{-3}\right)$} & \multicolumn{3}{c}{$\mathrm{CS}\left(10^{-3} \mathrm{~s}^{-1}\right)$} & \multicolumn{3}{c}{ CoagS $\left(10^{-3} \mathrm{~s}^{-1}\right)$} \\
\hline $\mathrm{O}$ & $\mathrm{T}$ & $\mathrm{A}$ & $\mathrm{O}$ & $\mathrm{T}$ & $\mathrm{A}$ & $\mathrm{O}$ & $\mathrm{T}$ & $\mathrm{A}$ \\
\hline Mean & 4.34 & 12.8 & 18.8 & 1.78 & 2.49 & 1.46 & 10.8 & 6.4 & 7.4 \\
Median & 1.9 & 1.2 & 1.7 & 1.75 & 2.10 & 1.23 & 7.5 & 5.0 & 5.8 \\
LMNB (unitless) & - & -0.12 & 0.15 & - & 0.00048 & -0.018 & - & -0.218 & -0.109 \\
\hline
\end{tabular}

Table 5. Mean values for nucleation event numbers for each site. $\mathrm{O}=$ observed, $\mathrm{T}=$ ternary simulation, $\mathrm{A}=$ activation simulation.

\begin{tabular}{|c|c|c|c|c|c|c|c|c|c|c|c|c|c|c|c|}
\hline & \multicolumn{3}{|c|}{ Pittsburgh } & \multicolumn{3}{|c|}{ Hyytiälä } & \multicolumn{3}{|c|}{ Atlanta } & \multicolumn{3}{|c|}{ St. Louis } & \multicolumn{3}{|c|}{ Po Valley } \\
\hline & $\mathrm{O}$ & $\mathrm{T}$ & A & $\mathrm{O}$ & $\mathrm{T}$ & A & $\mathrm{O}$ & $\mathrm{T}$ & A & $\mathrm{O}$ & $\mathrm{T}$ & A & $\mathrm{O}$ & $\mathrm{T}$ & A \\
\hline $\begin{array}{l}\text { Number of } \\
\text { total events }\end{array}$ & 109 & 104 & 137 & 107 & 95 & 100 & 108 & 135 & 138 & 102 & 121 & 177 & 145 & 147 & 141 \\
\hline $\begin{array}{l}\text { Number of } \\
\text { growth events } \\
\text { to } 50 \mathrm{~nm}\end{array}$ & 42 & 37 & 36 & 55 & 33 & 46 & 33 & 47 & 43 & 32 & 27 & 29 & 65 & 53 & 64 \\
\hline $\begin{array}{l}\text { Number of } \\
\text { growth events } \\
\text { to } 100 \mathrm{~nm}\end{array}$ & 13 & 10 & 18 & 19 & 10 & 13 & 17 & 11 & 9 & 17 & 18 & 13 & 40 & 39 & 49 \\
\hline
\end{tabular}

overpredict the observed values by at least a factor of 3 , as evidenced by the large differences in mean values but not medians (indicating a skewed distribution). Shown in Fig. 10b is the comparison between model and measured condensation sink. The modeled condensation sink is biased slightly low in the activation simulation (see Table 4), which may reflect a weakness in the model's representation of pre-existing, background accumulation mode aerosol. However, this small bias does not seem to be strong enough to compromise many of our nucleation metric evaluations. In the scaled ternary simulation, CS is skewed higher in the model, especially at larger condensation sinks, perhaps indicating a strong feedback between nucleation rates and condensation sink. Figure 10c is the CDF of a coagulational sink of $3 \mathrm{~nm}$ particles. The ternary and activation simulations show fair agreement with small negative bias. The differences in model-measurement agreement between the condensation and coagulation sinks are due to the growing nucleation mode making a significant contribution to the condensation sink (particularly in the ternary simulations) but a smaller contribution to the coagulation sink (only particles larger than the growing nucleation mode contribute to the coagulation sink).

\subsection{Contributions of organics to modeled and measured particle growth}

We also analyzed the relative contributions of sulfuric acid and low volatility organic vapors to the growth of nucleated particles in order to test whether the model underpredicts the SOA contribution to the growth rate. Figure 11 shows the annually averaged speciated growth rate for all sites. Sulfuric acid measurements were only available to us at Hyytiälä. As a result, only observations at Hyytiälä are broken down by
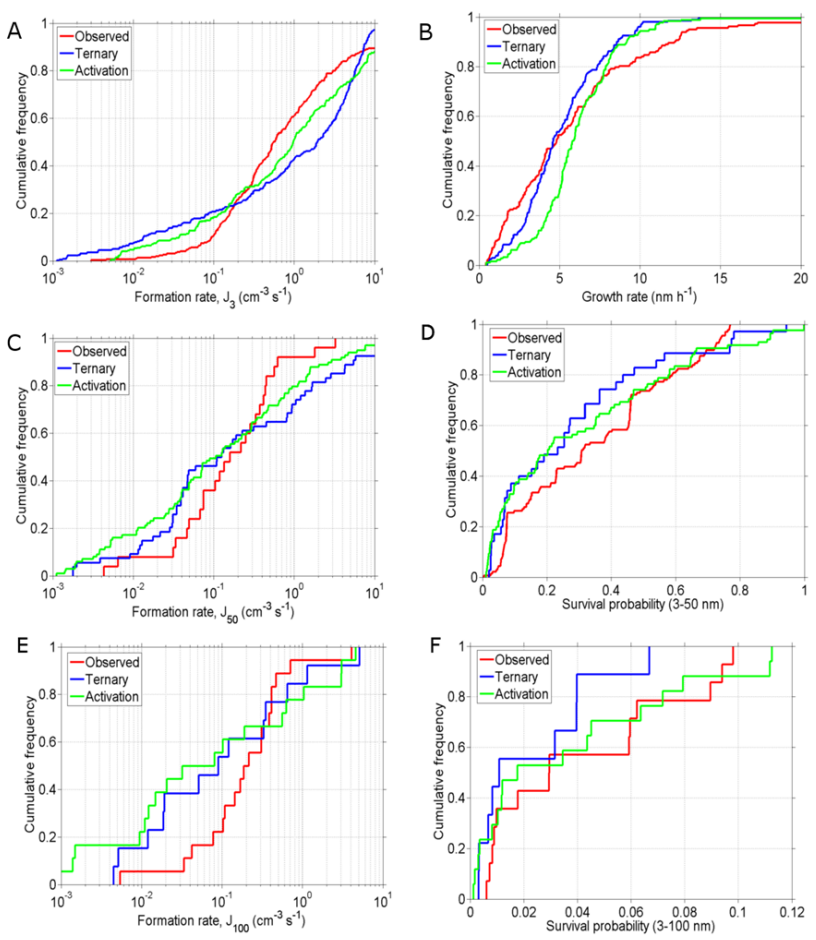

Fig. 9. Same as in Fig. 5, for modeled and measured nucleation metrics at San Pietro Capofiume, Po Valley (SPC).

organic or sulfuric acid growth. Total (nonspeciated) growth rate is instead plotted for the four other sites (yellow bars with green stripes in Fig. 11). The measurements at Hyytiälä and the model at most locations (Hyytiälä, St. Louis, Po Valley, and Atlanta) show a strong organic component in what 

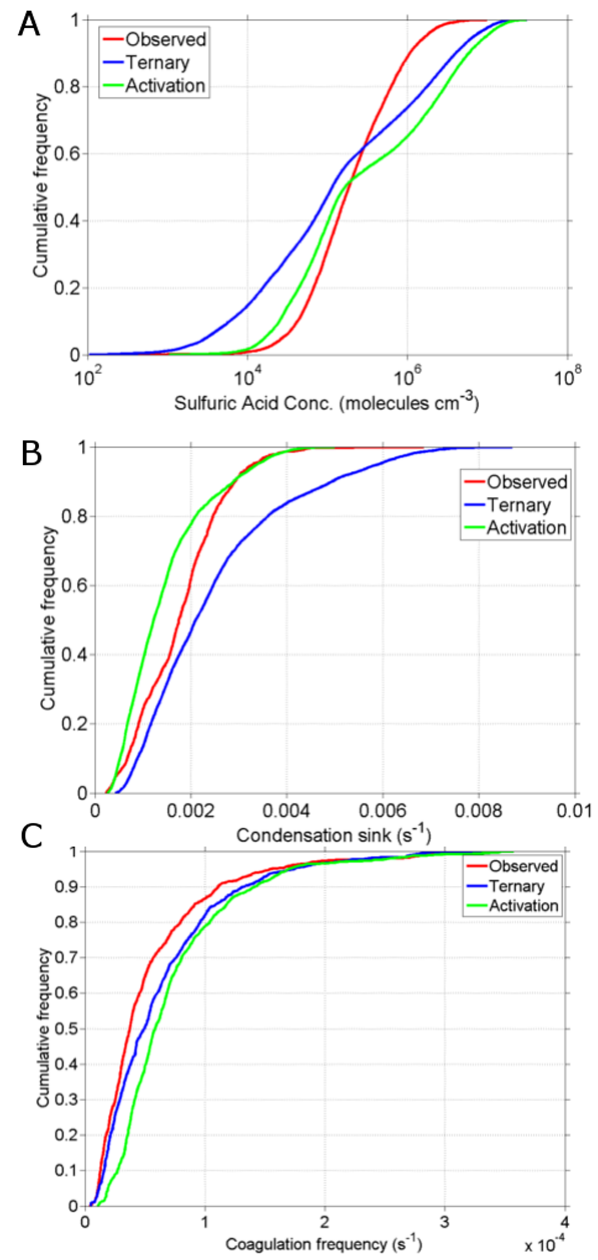

Fig. 10. Additional nucleation metrics at Hyytiälä for the ternary (with $10^{-5}$ tuning factor) and activation models and the measurements. (A) shows the CDF of the maximum daily sulfuric acid concentration. (B) is a CDF of modeled and measured condensation sink values. (C) shows the CDF of coagulation sink for $3 \mathrm{~nm}$ particles.

is condensing and causing particle growth (measurements at HYY: $2.5 \mathrm{~nm} \mathrm{~h}^{-1}$ organic, $0.4 \mathrm{~nm} \mathrm{~h}^{-1}$ sulfate, model at HYY: $1.6,0.1$, respectively). Sulfuric acid is not particularly an important component of the growth rate at Hyytiälä, but is more important for nucleation rates and frequency of events. This is consistent with findings in Riipinen et al. (2011). In contrast, Pittsburgh is the only site where more than $50 \%$ of the growth rate is due to sulfuric acid and not organics. This is realistic for Pittsburgh, a location heavily impacted by power plant emissions (Stanier et al., 2004). Although organics contribute the majority of the growth rate at Atlanta, St. Louis, and Po Valley, still roughly $30-40 \%$ of the growth rate appears to result from sulfuric acid condensation. This is likely not realistic for Atlanta in particular, which shows a strong organic signature in the growth rate (Kuang et al., 2009). For the Po Valley, recent observations suggest a larger contribu-

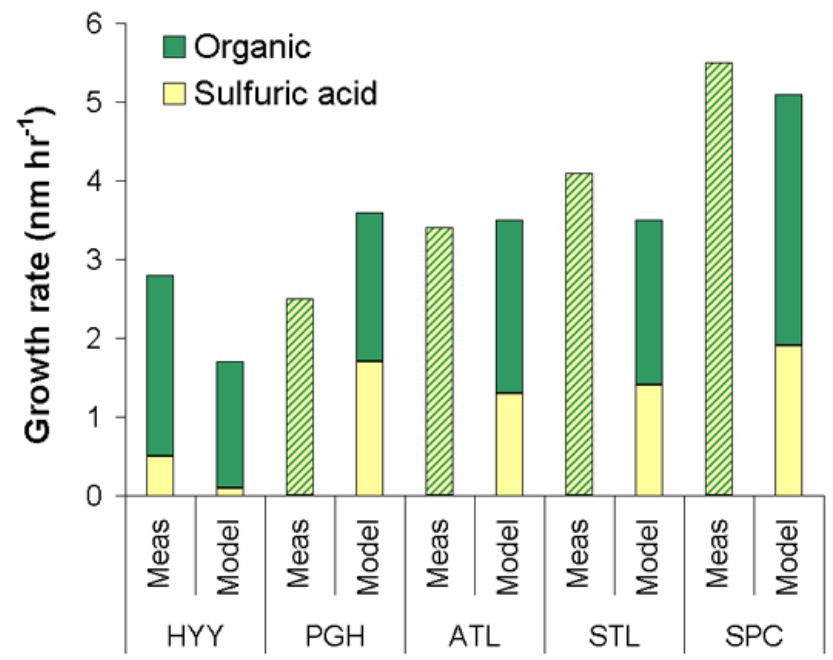

Fig. 11. Annually averaged growth rate as a function of condensing vapor chemical species, either low volatility organics or sulfuric acid, for observations and model (ternary nucleation with $10^{-5}$ tuning factor simulation) results at each of the five locations. Green shading represents organic condensation and yellow represents sulfuric acid. Sulfuric acid measurements (and therefore speciation analyses) were only available at Hyytiälä for the simulated time periods. For these sites without measurements, total growth rate is plotted without knowledge of breakdown between condensing vapor (yellow with green shading). Units are in $\mathrm{nm} \mathrm{h}^{-1}$.

tion of organics than predicted by the model (Paasonen et al., 2010), although these measurements refer to three case studies with very high growth rates $\left(9.5 \mathrm{~nm} \mathrm{~h}^{-1}\right)$. Though we cannot make definitive statements without additional data, it appears as if the model might modestly underpredict organic condensation in at least some locations, Atlanta in particular. It is possible that a missing source of SOA is potentially causing this underprediction. However, the model underpredicts organic condensation only slightly at Hyytiälä, which is the only location where we can make a valid comparison. Organic condensation has been shown to contribute up to $90 \%$ of growth rates at Mexico City (Smith et al., 2008), a level that is achieved at Hyytiälä but not any of our other 4 test locations.

\section{Conclusions}

We have presented a novel approach for evaluating aerosol models against observations of boundary layer nucleation, growth and CCN formation. Despite limitations in the nucleation and SOA parameterizations used in the model, we find that the global model, GEOS-Chem-TOMAS, does an acceptable job of reproducing observed boundary layer nucleation and growth events at the locations used in this study. A strength of the approach is that it compares a large number of nucleation and growth metrics $\left(J_{3}, \mathrm{GR}\right.$, coagulation and 
condensation sinks, etc.), which should help isolate individual processes biasing model predictions. The methodology presented for analyzing size distribution data applies to both measured and modeled size distribution output, and should be a useful tool for future studies. It builds on earlier methods presented in Dal Maso et al. (2005) and survival probability analysis in Pierce and Adams (2007), Kuang et al. (2009), and Kerminen et al. (2005). In addition, we have advanced the analysis performed by these previous authors by (1) analyzing longer datasets to get a climatology of nucleationrelevant parameters and (2) estimating the survival probability and CCN formation rates (Eqs. 6, 7). Together, these steps allow for a broader examination of nucleation events within the context of global CCN formation. We apply the method to five datasets and corresponding model runs with two sets of commonly used nucleation parameterizations.

Figure 12 summarizes our model-measurement comparison succinctly. For each site and each metric, we plot the $\log$-mean-normalized bias value (LMNB). LMNB is the average number of orders of magnitude error, e.g., a value of -0.3 means that the model underpredicts the measurements by about a factor of 2 . It is clear that the model tends to underpredict most metrics as all but ten of the bars in Fig. 12 fall at or below the dashed zero bias line. However, model predictions of quantities such as event frequency, nucleation rate, growth rate, and particle survival to $\mathrm{CCN}$ are within a factor of 2 when compared to quantities inferred directly from observations. More often, biases are within $50 \%$ (for example, growth rates at Pittsburgh and Hyytiälä, green and red bars in Fig. 12). Rarely, factor of 5 or larger discrepancies are observed, as is the case with nucleation rates $\left(J_{3}\right)$ at Atlanta and St. Louis (yellow and brown bars) where the model cannot resolve the sub-grid chemistry and physics in these urban locations. Given the gaps in our knowledge of nucleation and secondary organic aerosol, the modeled aerosol dynamics, SOA treatment, and nucleation theories perform reasonably well.

Median and mean survival probabilities to $100 \mathrm{~nm}$ (within a single day) are no more than $6 \%$ in the model and the measurements. Although this seems to be in disagreement with other observational studies that report survival probabilities of up to 20 and $25 \%$ (Kuang et al., 2009, Pierce et al. 2012), those studies did not consider a long enough climatology of nucleation events including more "ordinary" events that do not yield fast enough growth rates. In contrast, more nucleation events reach the $50 \mathrm{~nm}$ cutoff and survival probabilities span the entire range from 0 to 1 , as is expected. Growth rates were shown to be mostly dominated by organic species in both the model and the measurements at Hyytiälä. Condensation and coagulation sinks were both overpredicted and underpredicted in the model cases, although not by a large enough amount to significantly impact the nucleation metric calculations.

The overall success of the model does not imply that the current parameterizations are accurate representations of the

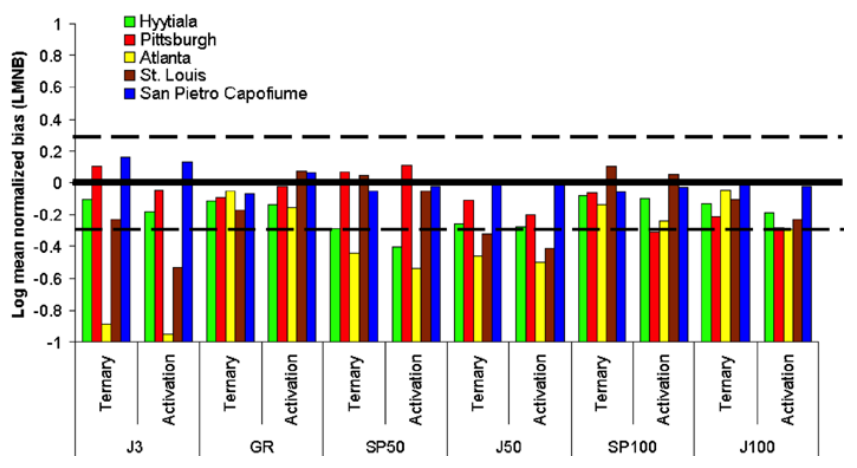

Fig. 12. Log-mean normalized bias (LMNB) values for each metric and each site for both the ternary and activation simulations. Solid line represents no model bias, whereas dashed lines signify biases of a factor of 2 (high and low). For each site and each metric, we plot the LMNB value. LMNB is the average number of orders of magnitude error, e.g., a value of -0.3 means that the model underpredicts the measurements by about a factor of 2 . The dashed line means zero bias in the model predictions.

real chemistry, only that the model tends to get an acceptable result on average. A better understanding of the nucleation mechanism should, in principle, lead to better model skill. Model predictions may benefit from fortuitous "error canceling". For example, the model may underestimate how much secondary organic material is available for condensation, but we treat secondary organic aerosol as nonvolatile, which maximizes how much material will remain in the condensed phase and cause particles to grow (Riipinen et al., 2011). Additionally, model predictions benefit from buffering in the aerosol microphysics system. For example, an overprediction of nucleation would contribute to an overprediction of condensation and coagulation sinks, which lead to lower growth rates, faster coagulational loss rates and lower survival probabilities. Thus, the formation of CCN-sized particles from nucleation (which is the product of the nucleation rate and survival probability) generally has less error than the error in the nucleation rate itself.

Because the model accuracy was found to be reasonable across the metrics for most locations, our results provide justification for the use of global models as tools for assessing the role of nucleation in the particle number and $\mathrm{CCN}$ budgets. The model-measurement comparisons have also helped us identify the processes that lead to biased model predictions. For example, growth rates are predicted well across the sites (Fig. 12), whereas nucleation rates are more biased, causing most of the bias in the $\mathrm{CCN}$ formation. Despite the use of a lower bound SOA source for organic growth, it is likely the nucleation rates and not the growth rates that cause a slight underprediction in quantities such as survival probability and CCN formation rates. We leave improved CCN contribution estimates and sensitivity studies for future work, which can now utilize the tested and evaluated GEOS-Chem-TOMAS global aerosol model. The generality 
of our conclusions would benefit from more detailed measurements in many parts of the atmosphere. Future modeling studies will especially benefit from long-term nucleation observations at rural or background locations, which provide ideal test conditions for coarse resolution global aerosol models. Lastly, since these results depend on longterm ground observations, we reiterate that the contributions of nucleation to $\mathrm{CCN}$ derived here reflect only the effect of nucleation and growth in the boundary layer. Models (Pierce et al., 2009b) and observations (Clarke et al., 1999) suggest that nucleation is frequent in the free troposphere and that it may contribute more to $\mathrm{CCN}$ than boundary layer nucleation (Merikanto et al., 2009).

Acknowledgements. This research was pursued with funds from the US Environmental Protection Agency under EPA Agreement RD-83337401-0 and STAR Grant RD-83503501. We would like to thank the Markku Kulmala research group for access to data (HYY). We would also like to thank Peter McMurry (ATL, STL), Ari Laaksonen (SPC), and Spyros Pandis (PGH) for access to their datasets. We also thank Peter McMurry for helpful comments on the manuscript. Finally, we would like to thank Tuuka Petäjä for the sulfuric acid measurements at Hyytiälä.

Edited by: D. Spracklen

\section{References}

Adams, P. J. and Seinfeld, J. H.: Predicting global aerosol size distributions in general circulation models, J. Geophys. Res.-Atmos., 107, 4370, doi:10.1029/2001jd001010, 2002.

Albrecht, B.: Aerosols, Cloud Microphysics, and Fractional Cloudiness, Science, 245, 1227-1230, doi:10.1126/science.245.4923.1227, 1989.

Auvray, M. and Bey, I. : Long-range transport to Europe: Seasonal variations and implications for the European ozone budget, J. Geophys. Res., 110, D11303, doi:10.1029/2004JD005503, 2005.

Ball, S. M., Hanson, D. R., Eisele, F. L., and McMurry, P. H.: Laboratory studies of particle nucleation: Initial results for $\mathrm{H}_{2} \mathrm{SO}_{4}$, $\mathrm{H}_{2} \mathrm{O}$, and $\mathrm{NH}_{3}$ vapors, J. Geophys. Res., 104, 23709-23718, doi:10.1029/1999JD900411, 1999.

Berndt, T., Böge, O., Stratmann, F., Heintzenberg, J., and Kulmala, M.: Rapid Formation of Sulfuric Acid Particles at Near-Atmospheric Conditions, Science, 307, 698-700, doi:10.1126/science.1104054, 2005.

Bey, I., Jacob, D. J., Yantosca, R. M., Logan, J. A., Field, B. D., Fiore, A. M., Li, Q. B., Liu, H. G. Y., Mickley, L. J., and Schultz, M. G.: Global modeling of tropospheric chemistry with assimilated meteorology: Model description and evaluation, J. Geophys. Res., 106, 23073-23095, 2001.

Bzdek, B. R., Ridge, D. P., and Johnston, M. V.: Amine exchange into ammonium bisulfate and ammonium nitrate nuclei, Atmos. Chem. Phys., 10, 3495-3503, doi:10.5194/acp-10-3495-2010, 2010.

Clarke, A. D., F. Eisele, V. N. Kapustin, K. Moore, D. Tanner, L. Mauldin, M. Litchy, B. Lienert, M. A. Carroll, and G. Albercook. Nucleation in the equatorial free troposphere: Favorable environments during PEM-Tropics, J. Geophys. Res., 104, 57355744, doi:10.1029/98JD02303, 1999.

Chen, M., Titcombe, M., Jiang, J., Jen, C., Kuang, C., Fischer, M. L., Eisele, F. L., Siepmann, J. I., Hanson, D. R., Zhao, J., and McMurry, P. H.: Acid-base chemical reaction model for nucleation rates in the polluted atmospheric boundary layer., Proceedings of the National Academy of Sciences of the United States of America, 109, 18713-18718, doi:10.1073/pnas.1210285109, 2012.

Dal Maso, M., Kulmala, M., Lehtinen, K. E. J., M. Mäkelä, J., Aalto, P., and O'Dowd, C. D.: Condensation and coagulation sinks and formation of nucleation mode particles in coastal and boreal forest boundary layers, J. Geophys. Res., 107, 8097, doi:10.1029/2001JD001053, 2002.

Dal Maso, M., Kulmala, M., Riipinen, I., Wagner, R., Hussein, T., Aalto, P. P., and Lehtinen, K. E. J.: Formation and growth of fresh atmospheric aerosols: eight years of aerosol size distribution data from SMEAR II, Hyytiala, Finland, Boreal Env. Res., 10, 323336, 2005.

Donahue, N. M., Robinson, A. L., Stanier, C. O., and Pandis, S. N.: Coupled Partitioning, Dilution, and Chemical Aging of Semivolatile Organics, Env. Sci. Tech., 40, 2635-2643, doi:10.1021/es052297c, 2006.

Erupe, M. E., Benson, D. R., Li, J., Young, L., Verheggen, B., Al-Refai. M., Tahboub, O., Cunningham, C., Frimpong, F., Viggiano, A.A., and Lee, S. Correlation of aerosol nucleation rate with sulfuric acid and ammonia in Kent, Ohio: An atmospheric observation, J. Geophys. Res., 115, D23216, doi:10.1029/2010JD013942, 2010.

Facchini, M. C., Mircea, M., Fuzzi, S., and Charlson, R. J.: Cloud albedo enhancement by surface-active organic solutes in growing droplets, Nature, 401, 257-259, 1999.

Gagné, S., Laakso, L., Petäjä, T., Kerminen, V., and Kulmala, M.: Analysis of one year of Ion DMPS data from the SMEAR II station, Finland, Tellus B, 60, 318-329, doi:10.1111/j.16000889.2008.00347.x, 2008.

Gagné, S., Nieminen, T., Kurtén, T., Manninen, H. E., Petäjä, T., Laakso, L., Kerminen, V.-M., Boy, M., and Kulmala, M.: Factors influencing the contribution of ion-induced nucleation in a boreal forest, Finland, Atmos. Chem. Phys., 10, 3743-3757, doi:10.5194/acp-10-3743-2010, 2010.

Guenther, A., Karl, T., Harley, P., Wiedinmyer, C., Palmer, P. I., and Geron, C.: Estimates of global terrestrial isoprene emissions using MEGAN (Model of Emissions of Gases and Aerosols from Nature), Atmos. Chem. Phys., 6, 3181-3210, doi:10.5194/acp-63181-2006, 2006.

Jaatinen, A., Hamed, A., Joutsensaari, J., Mikkonen, S., Birmili, W., Wehner, B., Spindler, G., Wiedensohler, A., Decesari, S., Mircea, M., Facchini, M. C., Junninen, H., Kulmala, M., Lehtinen, K. E. J., and Laaksonen, A.: A comparison of new particle formation events in the boundary layer at three different sites in Europe. Boreal Env. Res., 14, 481-498, 2009.

Jung, J. G., Pandis, S. N., and Adams, P. J.: Evaluation of nucleation theories in a sulfur-rich environment, Aerosol Sci. Tech., 45, 495-504, 2008.

Jung, J. G., Fountoukis, C., Adams, P. J., and Pandis, S. N.: Simulation of in situ ultrafine particle formation in the eastern United States using PMCAMx-UF, J. Geophys. Res., 115, D03203, doi:10.1029/2009JD012313, 2010. 
Kanakidou, M., Seinfeld, J. H., Pandis, S. N., Barnes, I., Dentener, F. J., Facchini, M. C., Van Dingenen, R., Ervens, B., Nenes, A., Nielsen, C. J., Swietlicki, E., Putaud, J. P., Balkanski, Y., Fuzzi, S., Horth, J., Moortgat, G. K., Winterhalter, R., Myhre, C. E. L., Tsigaridis, K., Vignati, E., Stephanou, E. G., and Wilson, J.: Organic aerosol and global climate modelling: a review, Atmos. Chem. Phys., 5, 1053-1123, doi:10.5194/acp-5-1053-2005, 2005.

Kazil, J., Stier, P., Zhang, K., Quaas, J., Kinne, S., O’Donnell, D., Rast, S., Esch, M., Ferrachat, S., Lohmann, U., and Feichter, J.: Aerosol nucleation and its role for clouds and Earth's radiative forcing in the aerosol-climate model ECHAM5-HAM, Atmos. Chem. Phys., 10, 10733-10752, doi:10.5194/acp-1010733-2010, 2010.

Kerminen, V.-M. and Kulmala, M: Analytical formulae connecting the "real" and the "apparent" nucleation rate and the nuclei number concentration for atmospheric nucleation events, J. Aerosol Sci., 33, 609-622, doi:10.1016/S0021-8502(01)00194-X, 2002

Kerminen, V.-M., Lihavainen, H., Komppula M., Viisanen, Y., and Kulmala, M.: Direct observational evidence linking atmospheric aerosol formation and cloud droplet activation, Geophys. Res. Lett., 32, L14803, doi:10.1029/2005GL023130, 2005.

Kerminen, V.-M., Paramonov, M., Anttila, T., Riipinen, I., Fountoukis, C., Korhonen, H., Asmi, E., Laakso, L., Lihavainen, H., Swietlicki, E., Svenningsson, B., Asmi, a., Pandis, S. N., Kulmala, M., and Petäjä, T.: Cloud condensation nuclei production associated with atmospheric nucleation: a synthesis based on existing literature and new results, Atmos. Chem. Phys., 12, 1203712059, doi:10.5194/acp-12-12037-2012, 2012.

Kirkby, J., Curtius, J., Almeida, J., Dunne, E., Duplissy, J., Ehrhart, S., Franchin, A., Gagne, S., Ickes, L., Kurten, A., Kupc, A., Metzger, A., Riccobono, F., Rondo, L., Schobesberger, S., Tsagkogeorgas, G., Wimmer, D., Amorim, A., Bianchi, F., Breitenlechner, M., David, A., Dommen, J., Downard, A., Ehn, M., Flagan, R. C., Haider, S., Hansel, A., Hauser, D., Jud, W., Junninen, H., Kreissl, F., Kvashin, A., Laaksonen, A., Lehtipalo, K., Lima, J., Lovejoy, E. R., Makhmutov, V., Mathot, S., Mikkila, J., Minginette, P., Mogo, S., Nieminen, T., Onnela, A., Pereira, P., Petaja, T., Schnitzhofer, R., Seinfeld, J. H., Sipila, M., Stozhkov, Y., Stratmann, F., Tome, A., Vanhanen, J., Viisanen, Y., Vrtala, A., Wagner, P. E., Walther, H., Weingartner, E., Wex, H., Winkler, P. M., Carslaw, K. S., Worsnop, D. R., Baltensperger, U., and Kulmala, M.: Role of sulphuric acid, ammonia and galactic cosmic rays in atmospheric aerosol nucleation, Nature, 476, 429-433, doi:10.1038/nature10343, 2011.

Kuang, C., McMurry, P. H., McCormick, A. V. and Eisele, F. L.: Dependence of nucleation rates on sulfuric acid vapor concentration in diverse atmospheric locations, J. Geophys. Res., 113, D10209, doi:10.1029/2007JD009253, 2008.

Kuang, C., McMurry, P. H., and McCormick, A. V.: Determination of cloud condensation nuclei production from measured new particle formation events, Geophys. Res. Lett., 36, L09822, doi:10.1029/2009GL037584, 2009.

Kuhns, H., Green, M., and Etyemezian, V.: Big Bend Regional Aerosol and Visibility Observational (BRAVO) Study Emissions Inventory, technical report prepared for the BRAVO Steering Committee, 2001.

Kulmala, M., Pirjola, L., and Makela, J. M.: Stable sulphate clusters as a source of new atmospheric particles, Nature, 404, 66-69, doi:10.1038/35003550, 2000.

Kulmala, M., Vehkamaki, H., Petaja, T., Dal Maso, M., Lauri, A., Kerminen, V. M., Birmili, W., and McMurry, P. H. Formation and growth rates of ultrafine atmospheric particles: a review of observations, J. Aerosol Sci., 35, 143-176, doi:10.1016/j.jaerosci.2003.10.003, 2004a.

Kulmala, M., Laakso, L., Lehtinen, K. E. J., Riipinen, I., Dal Maso, M., Anttila, T., Kerminen, V.-M., Hõrrak, U., Vana, M., and Tammet, H.: Initial steps of aerosol growth, Atmos. Chem. Phys., 4, 2553-2560, doi:10.5194/acp-4-2553-2004, 2004b.

Kulmala, M., Kontkanen, J., Junninen, H., Lehtipalo, K., Manninen, H. E., Nieminen, T., Petäjä, T., Sipilä, M., Schobesberger, S., Rantala, P., Franchin, A., Jokinen, T., Järvinen, E., Äijälä, M., Kangasluoma, J., Hakala, J., Aalto, P. P., Paasonen, P., Mikkilä, J., Vanhanen, J., Aalto, J., Hakola, H., Makkonen, U., Ruuskanen, T., Mauldin, R. L., Duplissy, J., Vehkamäki, H., Bäck, J., Kortelainen, A., Riipinen, I., Kurtén, T., Johnston, M. V, Smith, J. N., Ehn, M., Mentel, T. F., Lehtinen, K. E. J., Laaksonen, A., Kerminen, V.-M., and Worsnop, D. R.: Direct observations of atmospheric aerosol nucleation, Science (New York, N.Y.), 339, 943-6, doi:10.1126/science.1227385, 2013.

Kurtén, T., Loukonen, V., Vehkamäki, H., and Kulmala, M.: Amines are likely to enhance neutral and ion-induced sulfuric acid-water nucleation in the atmosphere more effectively than ammonia, Atmos. Chem. Phys., 8, 4095-4103, doi:10.5194/acp-8-4095-2008, 2008.

Laakso, L., Gagné, S., Petäjä, T., Hirsikko, A., Aalto, P. P., Kulmala, M., and Kerminen, V.-M.: Detecting charging state of ultrafine particles: instrumental development and ambient measurements, Atmos. Chem. Phys., 7, 1333-1345, doi:10.5194/acp-71333-2007, 2007.

Laaksonen, A., Hamed, A., Joutsensaari, J., Hiltunen, L., Cavalli, F., Junkermann, W., Asmi, A. Fuzzi, S., and Facchini, M. C.: Cloud condensation nucleus production from nucleation events at a highly polluted region, Geophys. Res. Lett., 32, L06812, doi:10.1029/2004GL022092, 2005.

Lee, L. A., Pringle, K. J., Reddington, C. L., Mann, G. W., Stier, P., Spracklen, D. V., Pierce, J. R., and Carslaw, K. S.: The magnitude and causes of uncertainty in global model simulations of cloud condensation nuclei, Atmos. Chem. Phys. Discuss., 13, 62956378, doi:10.5194/acpd-13-6295-2013, 2013.

Lee, Y. H., Chen, K., and Adams, P. J.: Development of a global model of mineral dust aerosol microphysics, Atmos. Chem. Phys., 9, 2441-2458, doi:10.5194/acp-9-2441-2009, 2009.

Mäkelä, J. M., Aalto, P., Jokinen, V., Pohja, T., Nissinen, A., Palmroth, S., Markkanen, T., Seitsonen, K., Lihavainen, H., and Kulmala, M.: Observations of ultrafine aerosol particle formation and growth in boreal forest, Geophys. Res. Lett., 24, 1219-1222, doi:10.1029/97GL00920, 1997

Makkonen, R., Asmi, A., Korhonen, H., Kokkola, H., Järvenoja, S., Räisänen, P., Lehtinen, K. E. J., Laaksonen, A., Kerminen, V.M., Järvinen, H., Lohmann, U., Bennartz, R., Feichter, J., and Kulmala, M.: Sensitivity of aerosol concentrations and cloud properties to nucleation and secondary organic distribution in ECHAM5-HAM global circulation model, Atmos. Chem. Phys., 9, 1747-1766, doi:10.5194/acp-9-1747-2009, 2009.

Manninen, H. E., Nieminen, T., Riipinen, I., Yli-Juuti, T., Gagné, S., Asmi, E., Aalto, P. P., Petäjä, T., Kerminen, V.-M., and Kulmala, M.: Charged and total particle formation and growth rates 
during EUCAARI 2007 campaign in Hyytiälä, Atmos. Chem. Phys., 9, 4077-4089, doi:10.5194/acp-9-4077-2009, 2009.

Merikanto, J., Napari, I., Vehkamäki, H., Anttila, T., and Kulmala, M.: New parameterization of sulfuric acid-ammonia-water ternary nucleation rates at tropospheric conditions, J. Geophys. Res., 112, D15207, doi:10.1029/2006JD007977, 2007.

Merikanto, J., Spracklen, D. V., Mann, G. W., Pickering, S. J., and Carslaw, K. S.: Impact of nucleation on global CCN, Atmos. Chem. Phys., 9, 8601-8616, 2009,

http://www.atmos-chem-phys.net/9/8601/2009/.

Napari, I., Kulmala, M., and Vehkamaki, H.: Ternary nucleation of inorganic acids, ammonia, and water, J. Chem. Phys., 117, 84188425, doi:10.1063/1.1511722, 2002.

Nenes, A., R. J. Charlson, M. C. Facchini, M. Kulmala, A. Laaksonen, and J. H. Seinfeld, Can chemical effects on cloud droplet number rival the first indirect effect?, Geophys. Res. Lett., 29, 1848, doi:10.1029/2002GL015295, 2002.

Olivier, J. G. J., Bouwman, A. F., Van der Maas, C. W. M., Berdowski, J. J. M., Veldt, C., Bloos, J. P. J., Visschedijk, A. J. H., Zandveld, P. Y. J., and Haverlag, J. L.: Description of EDGAR Version 2.0: A set of global emission inventories of greenhouse gases and ozone-depleting substances for all anthropogenic and most natural sources on a per country basis and on $1 x 1$ grid. National Institute of Public Health and the Environment (RIVM) report no. 771060 002, Netherlands Organization for Applied Scientific Research (TNO), 1996.

Paasonen, P., Nieminen, T., Asmi, E., Manninen, H. E., Petäjä, T., Plass-Dülmer, C., Flentje, H., Birmili, W., Wiedensohler, A., Hõrrak, U., Metzger, A., Hamed, A., Laaksonen, A., Facchini, M. C., Kerminen, V.-M., and Kulmala, M.: On the roles of sulphuric acid and low-volatility organic vapours in the initial steps of atmospheric new particle formation, Atmos. Chem. Phys., 10, 11223-11242, doi:10.5194/acp-10-11223-2010, 2010.

Pandis, S. N., Baltensperger, U., Wolfenbarger, J. K., Seinfeld, J. H., Inversion of aerosol data from the epiphaniometer, J. Aerosol Sci., 22, 417-428, doi:10.1016/0021-8502(91)90002-Y, 1991.

Petäjä, T., Mauldin, III, R. L., Kosciuch, E., McGrath, J., Nieminen, T., Paasonen, P., Boy, M., Adamov, A., Kotiaho, T., and Kulmala, M.: Sulfuric acid and $\mathrm{OH}$ concentrations in a boreal forest site, Atmos. Chem. Phys., 9, 7435-7448, doi:10.5194/acp9-7435-2009, 2009.

Pierce, J. R. and Adams, P. J.: Efficiency of cloud condensation nuclei formation from ultrafine particles, Atmos. Chem. Phys., 7, 1367-1379, doi:10.5194/acp-7-1367-2007, 2007.

Pierce, J. R. and Adams, P. J.: A Computationally Efficient Aerosol Nucleation/ Condensation Method: PseudoSteady-State Sulfuric Acid, Aerosol Sci. Tech., 43, 216, doi:10.1080/02786820802587896, 2009a.

Pierce, J. R. and Adams, P. J.: Uncertainty in global CCN concentrations from uncertain aerosol nucleation and primary emission rates, Atmos. Chem. Phys., 9, 1339-1356, doi:10.5194/acp-91339-2009, 2009b.

Pierce, J. R., Chen, K., and Adams, P. J.: Contribution of primary carbonaceous aerosol to cloud condensation nuclei: processes and uncertainties evaluated with a global aerosol microphysics model, Atmos. Chem. Phys., 7, 5447-5466, doi:10.5194/acp-75447-2007, 2007.

Pierce, J. R., Riipinen, I., Kulmala, M., Ehn, M., Petäjä, T., Junninen, H., Worsnop, D. R., and Donahue, N. M.: Quantification of the volatility of secondary organic compounds in ultrafine particles during nucleation events, Atmos. Chem. Phys., 11, 90199036, doi:10.5194/acp-11-9019-2011, 2011.

Pierce, J. R., Leaitch, W. R., Liggio, J., Westervelt, D. M., Wainwright, C. D., Abbatt, J. P. D., Ahlm, L., Al-Basheer, W., Cziczo, D. J., Hayden, K. L., Lee, A. K. Y., Li, S.-M., Russell, L. M., Sjostedt, S. J., Strawbridge, K. B., Travis, M., Vlasenko, A., Wentzell, J. J. B., Wiebe, H. A., Wong, J. P. S., and Macdonald, A. M.: Nucleation and condensational growth to CCN sizes during a sustained pristine biogenic SOA event in a forested mountain valley, Atmos. Chem. Phys., 12, 3147-3163, doi:10.5194/acp-12-3147-2012, 2012.

Qian, S, Sakurai H., and McMurry, P. Characteristics of regional nucleation events in urban East St. Louis, Atmos. Environ., 41, 4119-4127, doi:10.1016/j.atmosenv.2007.01.011, 2007.

Raymond, T. M., and Pandis, S. N.: Formation of cloud droplets by multicomponent organic particles, J. Geophys. Res., 108, 4469, doi:10.1029/2003JD003503, 2003.

Riipinen, I., Sihto, S.-L., Kulmala, M., Arnold, F., Dal Maso, M., Birmili, W., Saarnio, K., Teinilä, K., Kerminen, V.-M., Laaksonen, A., and Lehtinen, K. E. J.: Connections between atmospheric sulphuric acid and new particle formation during QUEST III-IV campaigns in Heidelberg and Hyytiälä, Atmos. Chem. Phys., 7, 1899-1914, doi:10.5194/acp-7-1899-2007, 2007.

Riipinen, I., Pierce, J. R., Yli-Juuti, T., Nieminen, T., Häkkinen, S., Ehn, M., Junninen, H., Lehtipalo, K., Petäjä, T., Slowik, J., Chang, R., Shantz, N. C., Abbatt, J., Leaitch, W. R., Kerminen, V.-M., Worsnop, D. R., Pandis, S. N., Donahue, N. M., and Kulmala, M.: Organic condensation: a vital link connecting aerosol formation to cloud condensation nuclei (CCN) concentrations, Atmos. Chem. Phys., 11, 3865-3878, doi:10.5194/acp11-3865-2011, 2011.

Seinfeld, J. H. and Pandis, S. N.: Atmospheric Chemistry and Physics - From Air Pollution to Climate Change (2nd Edition), John Wiley \& Sons, 2006.

Sihto, S.-L., Kulmala, M., Kerminen, V.-M., Dal Maso, M., Petäjä, T., Riipinen, I., Korhonen, H., Arnold, F., Janson, R., Boy, M., Laaksonen, A., and Lehtinen, K. E. J.: Atmospheric sulphuric acid and aerosol formation: implications from atmospheric measurements for nucleation and early growth mechanisms, Atmos. Chem. Phys., 6, 4079-4091, doi:10.5194/acp-64079-2006, 2006.

Sipilä, M., Berndt, T., Petäjä, T., Brus, D., Vanhanen, J., Stratmann, F., Patokoski, J., Mauldin, R. L., Hyvärinen, A.P., Lihavainen, H. and Kulmala, M.: The Role of Sulfuric Acid in Atmospheric Nucleation, Science, 327, 1243-1246, doi:10.1126/science.1180315, 2010.

Smith, J. N., Dunn, M. J., VanReken, T. M., Iida, K., Stolzenburg, M. R., McMurry, P. H., and Huey, L. G.: Chemical composition of atmospheric nanoparticles formed from nucleation in Tecamac, Mexico: Evidence for an important role for organic species in nanoparticle growth, Geophys. Res. Lett., 35, L04808, doi:10.1029/2007GL032523, 2008.

Spracklen, D. V., Carslaw, K. S., Merikanto, J., Mann, G. W., Reddington, C. L., Pickering, S., Ogren, J. A., Andrews, E., Baltensperger, U., Weingartner, E., Boy, M., Kulmala, M., Laakso, L., Lihavainen, H., Kivekäs, N., Komppula, M., Mihalopoulos, N., Kouvarakis, G., Jennings, S. G., O'Dowd, C., Birmili, W., Wiedensohler, A., Weller, R., Gras, J., Laj, P., Sellegri, K., Bonn, 
B., Krejci, R., Laaksonen, A., Hamed, A., Minikin, A., Harrison, R. M., Talbot, R., and Sun, J.: Explaining global surface aerosol number concentrations in terms of primary emissions and particle formation, Atmos. Chem. Phys., 10, 4775-4793, doi:10.5194/acp-10-4775-2010, 2010.

Spracklen, D. V., Jimenez, J. L., Carslaw, K. S., Worsnop, D. R., Evans, M. J., Mann, G. W., Zhang, Q., Canagaratna, M. R., Allan, J., Coe, H., McFiggans, G., Rap, A., and Forster, P.: Aerosol mass spectrometer constraint on the global secondary organic aerosol budget, Atmos. Chem. Phys., 11, 12109-12136, doi:10.5194/acp-11-12109-2011, 2011.

Stanier, C., Khlystov, A., and Pandis, S. N.: Nucleation Events during the Pittsburgh Air Quality Study: Description and Relation to Key Meteorological, Gas Phase, and Aerosol Parameters, Aerosol Sci. Tech., 38, 253-264, 2004.

Stevens, R. G., Pierce, J. R., Brock, C. A., Reed, M. K., Crawford, J. H., Holloway, J. S., Ryerson, T. B., Huey, L. G., and Nowak, J. B.: Nucleation and growth of sulfate aerosol in coal-fired power plant plumes: sensitivity to background aerosol and meteorology, Atmos. Chem. Phys., 12, 189-206, doi:10.5194/acp-12-189-2012, 2012.

Stolzenburg, M. R., McMurry, P. H., Sakurai, H., Smith, J. N., Mauldin III, R. L., Eisele, F. L., and Clement, C. F.:Growth rates of freshly nucleated atmospheric particles in Atlanta, J. Geophys. Res., 110, D22S05, doi:10.1029/2005JD005935, 2005.

Streets, D. G., Bond, T. C., Carmichael, G. R., Fernandes, S. D., Fu, Q., He, D., Klimont, Z., Nelson, S. M., Tsai, N. Y., Wang, M. Q., Woo, J-H., and Yarber, K. F.: An inventory of gaseous and primary aerosol emissions in Asia in the year 2000, J. Geophys. Res., 108, 8809, doi:10.1029/2002JD003093, 2003.

Trivitayanurak, W., Adams, P. J., Spracklen, D. V., and Carslaw, K. S.: Tropospheric aerosol microphysics simulation with assimilated meteorology: model description and intermodel comparison, Atmos. Chem. Phys., 8, 3149-3168, doi:10.5194/acp-83149-2008, 2008.

Twomey, S. A.: Pollution and Cloud Albedo, Eos. T. Am. Geophys. Un., 58, 797-797, 1977.

Twomey, S. and Wojciechowski, T. A.: Observations of the geographical variation of cloud nuclei, J. Atmos. Sci., 26, 648-651, 1969.

Tzivion (Tzitzvashvili), S., Feingold, G., and Levin, Z.: An Efficient Numerical Solution to the Stochastic Collection Equation. J. Atmos. Sci., 44, 3139-3149, doi:10.1175/15200469(1987)044<3139:AENSTT>2.0.CO;2, 1987
Vakkari, V., Laakso, H., Kulmala, M., Laaksonen, A., Mabaso, D., Molefe, M., Kgabi, N., and Laakso, L.: New particle formation events in semi-clean South African savannah, Atmos. Chem. Phys., 11, 3333-3346, doi:10.5194/acp-11-3333-2011, 2011.

van der Werf, G. R., Randerson, J. T., Giglio, L., Collatz, G. J., Kasibhatla, P. S., and Arellano Jr., A. F.: Interannual variability in global biomass burning emissions from 1997 to 2004, Atmos. Chem. Phys., 6, 3423-3441, doi:10.5194/acp-6-3423-2006, 2006.

Vehkamaki, H., Napari, I., Kulmala, M., and Noppel, M.: Stable ammonium bisulfate clusters in the atmosphere, Phys. Rev. Lett., 93, doi:10.1103/PhysRevLett.93.148501, 2004.

Vuollekoski, H., Nieminen, T., Paasonen, P., Sihto, S.-L., Boy, M., Manninen, H., Lehtinen, K., Kerminen, V.-M., and Kulmala, M.: Atmospheric nucleation and initial steps of particle growth: $\mathrm{Nu}-$ merical comparison of different theories and hypotheses, Atmos. Res., 98, 229-236, doi:10.1016/j.atmosres.2010.04.007, 2010.

Wang, M. and Penner, J. E.: Aerosol indirect forcing in a global model with particle nucleation, Atmos. Chem. Phys., 9, 239-260, doi:10.5194/acp-9-239-2009, 2009.

Weber, R. J., Marti, J., McMurry, P. H., Eisele, F. L., Tanner, D. J., and Jefferson, A.: Measured atmospheric new particle formation rates: implications for nucleation mechanisms, Chem. Eng. Comm., 151, 53-64, 1996.

Woo, K. S., Chen, D. R., Pui, D. Y. H., and McMurry, P. H.: Measurement of Atlanta Aerosol Size Distributions: Observations of Ultrafine Particle Events, Aerosol Sci. Technol., 34, 75-87, 2001.

Yu, F. and Luo, G.: Simulation of particle size distribution with a global aerosol model: contribution of nucleation to aerosol and CCN number concentrations, Atmos. Chem. Phys., 9, 76917710, doi:10.5194/acp-9-7691-2009, 2009.

Yu, F. and Turco, R. P.: The size-dependent charge fraction of sub-3$\mathrm{nm}$ particles as a key diagnostic of competitive nucleation mechanisms under atmospheric conditions, Atmos. Chem. Phys., 11, 9451-9463, doi:10.5194/acp-11-9451-2011, 2011

Zhang, R., Suh, I., Zhao, J., Zhang, D., Fortner, E. C., Tie, X., Molina, L. T. and Molina, M. J.: Atmospheric New Particle Formation Enhanced by Organic Acids, Science, 304, 1487-1490, doi:10.1126/science.1095139, 2004.

Zhao, J., Smith, J. N., Eisele, F. L., Chen, M., Kuang, C., and McMurry, P. H.: Observation of neutral sulfuric acid-amine containing clusters in laboratory and ambient measurements, Atmos. Chem. Phys., 11, 10823-10836, doi:10.5194/acp-1110823-2011, 2011. 